\title{
Death-associated protein kinase 3 (DAPK3) contributes to intestinal epithelial wound healing and the resolution of experimental colitis in mice
}

Huey-Miin Chen ${ }^{1}$, David A. Carlson², Timothy A.J. Haystead ${ }^{2}$, and Justin A. MacDonald ${ }^{1, *}$

\footnotetext{
${ }^{1}$ Department of Biochemistry \& Molecular Biology, Cumming School of Medicine, University of Calgary, 3280 Hospital Drive NW, Calgary, AB, T2N 4Z6, Canada

${ }^{2}$ Department of Pharmacology \& Cancer Biology, Duke University School of Medicine, Durham, NC, 27710, USA
}

* Correspondence to: Justin MacDonald, Department of Biochemistry \& Molecular Biology, University of Calgary, 3280 Hospital Drive NW, Calgary, AB, T2N 4Z6. Tel: 403-210-8433; Email:jmacdo@ucalgary.ca 


\begin{abstract}
Various signaling molecules affecting epithelial restitution and wound healing are dysregulated in ulcerative colitis. Recent evidence demonstrates the necessity of Hippo-YAP/TAZ signaling, interceded by cytoskeletal remodeling, for intestinal regeneration. Death-associated protein kinase 3 (DAPK3) is a regulator of actin cytoskeleton reorganization that controls proliferation and apoptosis. Pharmacological inhibition of DAPK3 in Caco-2 human intestinal epithelial cells (IECS) with the HS38 compound augmented cell proliferation and enhanced wound closure. This phenotype corresponded with the increased colocalization of Yes-associated protein (YAP) with F-actin, which is indicative of YAP activation. The administration of HS38 impeded the resolution of intestinal injury and attenuated epithelial-specific proliferation after acute colitis induced by dextran-sodium-sulphate (DSS) in mice. During recovery from DSS-induced colitis, IEC proliferation was repressed, and mice exhibited increased disease severity when HS38 was applied to inhibit DAPK3. Moreover, HS38 treatment increased YAP nuclear localization in IECs, an indicator of signal activation. In summary, this study established DAPK3 as a key factor in intestinal epithelial regeneration and colitis progression by way of YAP signaling. Nevertheless, the role that DAPK3 play in different cell types will need further investigation to decipher the full consequence of DAPK3 inhibition on epithelial homeostasis.
\end{abstract}

\title{
1. INTRODUCTION
}

Intestinal epithelial cells (IECS) that line the gastrointestinal tract provide a physical and biochemical barrier that separate the host's internal milieu from foreign antigens and microbial pathogens present in the lumen (Kagnoff, 2014; Pastorelli et al, 2013; Peterson \& Artis, 2014; Sanchez de Medina et al, 2014). Moreover, the epithelium serves as a communication hub for the intestinal mucosa by disseminating luminal events to the sub-epithelial immune compartment and participating in the coordination of mucosal defense and homeostasis (Kagnoff, 2014; Sanchez de Medina et al, 2014). Not surprisingly, altered IEC function is frequently detected in ulcerative colitis (UC) patients (Buning et al, 2012; Chang et al, 2017; Haberman et al, 2019; Issenman et al, 1993), and has been proposed as a potential etiologic 
factor for UC (Pastorelli et al, 2013). Epithelial integrity may be provisionally weakened by physiological inflammation or minor trauma (Hageman et al, 2020; Luissint et al, 2016). But, as the balance between pro- and anti-inflammatory stimuli is perpetually disturbed in UC (Strober \& Fuss, 2011), epithelial regeneration may be altered so that normal epithelial barrier function is not restored. Inefficacious wound healing can give rise to altered epithelial architecture, impaired barrier function, and intestinal neoplasia which further aggravate the inflammatory state (Koch \& Nusrat, 2012; Leoni et al, 2015). Therefore, rapid, and complete epithelial wound healing is essential for intestinal health and resolution of UC.

Various signaling molecules integral to epithelial restitution and wound healing are dysregulated in UC; examples include among others: 1) elevated expression of Wnt5a, a noncanonical Wingless-related integration site (Wnt) ligand that facilitates crypt regeneration in wound-associated epithelia (Miyoshi et al, 2012) and paradoxically imparts susceptibility to experimental murine colitis (Sato et al, 2015); 2) increased production of transforming growth factor- $\beta 1$ (TGF- $\beta 1$ ), an anti-inflammatory cytokine and inducer of tight junction protein and collagen expression (Del Zotto et al, 2003; Howe et al, 2005; Nigdelioglu et al, 2016) that has diminished effect on IECS isolated from IBD patients, partly due to the concurrent increase of TGF-ß1-inhibitory molecule Smad7 (Monteleone et al, 2004); and 3) constitutive activation of signal transducer and activator of transcription (STAT)-3, a pro-proliferative, anti-apoptotic factor essential for the regeneration of epithelium in response to injury that perpetuates and worsens UC despite its protective attributes (Nguyen et al, 2015).

In recent years, research has brought forward the Hippo pathway as a potential therapeutic target for UC. Dysregulation of the Hippo pathway was found in UC patients as well as multiple models of experimental colitis (Deng et al, 2018; Nterma et al, 2020; Xie et al, 2021). Evidence suggests that the major effectors of Hippo pathway, the Yes-associated protein (YAP) and the transcriptional co-activator with PDZ-binding motif (TAZ), link inflammation to epithelial regeneration through their integration of mechanical cues with growth factor signaling (Piccolo et al, 2014). Notably, crosstalk between the Hippo/Wnt and the TGF- $\beta 1 / S T A T 3$ pathways (Gruber 
et al, 2016; Park et al, 2015; Qin et al, 2018) exposes an inherently complex role for Hippo signaling in intestinal regeneration that requires further investigation in UC (Xie et al, 2021).

Death-associated protein kinase-3 (DAPK3) was also recently identified to be a potential key factor in UC progression (Chen \& MacDonald, 2021). DAPK3 contributes to cell growth in colon carcinoma cell lines (Togi et al, 2011), as well as autophagy induction (Li et al, 2021) and wound closure in gastric carcinoma cell lines (Li et al, 2015). Furthermore, the reduction of focal adhesion kinase (FAK) activity found with ectopic expression of DAPK3 (Nehru et al, 2013), suggests the kinase may also contribute to adhesion regulation during epithelial wound repair, to influence IEC proliferation and survival during UC progression (Owen et al, 2011). However, the significance of DAPK3 within these contexts has yet to be directly assessed in experimental models of UC.

While the impairment of several conserved signaling pathways is associated with intestinal epithelial dysfunction in UC (Koch \& Nusrat, 2012; Leoni et al, 2015; Xie et al, 2021), the intricacies of many effector networks involved in the restoration of epithelial homeostasis after injury and/or inflammation are not fully understood. We investigated whether DAPK3 may play a role in epithelial repair and/or UC disease progression given that DAPK3 has been linked to key signaling pathways that coordinate epithelial regeneration after injury. Central to this investigation is the recent availability of ATP-competitive, small molecule inhibitors of DAPK3 that display high specificity and great potency, while bypassing the chemical liabilities that are inherent to other compounds (Al-Ghabkari et al, 2016; Carlson et al, 2013; Carlson et al, 2018).

\section{METHODS}

2.1. Materials - The small molecule inhibitors HS38, HS56 and HS94 were synthesized as described previously (Carlson et al, 2013; Carlson et al, 2018). The Click-iT EdU Cell Proliferation Kit for Imaging, Alexa Fluor 488 (\#C10337) and 4',6-diamidino-2-phenylindole (DAPI; \#62248) were purchased from Invitrogen-ThermoFisher Scientific. The Phalloidin-iFluor 647 reagent (\#176759) was from Abcam (Cambridge, MA). Multiple antibodies were obtained from Cell Signaling Technology (Danvers, MA), including YAP (D8H1X) XP ${ }^{\oplus}$ rabbit mAb (\#14074), phosphor[Ser127]-YAP (D9W2I) rabbit mAb (\#13008), phospho[Ser397]-YAP (D1E7Y) rabbit mAb 
(\#13619), YAP/TAZ (D24E4) rabbit mAb (\#8418), phospho[Thr35]-MOB1 (D2F10) rabbit mAb (\#8699), MOB1 (E1N9D) rabbit mAb (\#13730), LATS1 (C66B5) rabbit mAb, (\#3477), GAPDH (14C10) rabbit mAb (\#2118), Ki-67 (D3B5) rabbit mAb (\#12202), MST1 rabbit IgG (\#3682) and MST2 rabbit IgG (\#3952). DAPK3 rabbit IgGs \#2928 and \#TA313745 were obtained from Cell Signaling and Origene (Rockville, MD), respectively. Cy3-conjugated AffiniPure donkey anti-rabbit IgG (\#711-165-152) was from Jackson ImmunoResearch, and dextran sodium sulphate (DSS, 3650 kDa; \#0216011090) was from MP Biomedicals (Solon, OH).

2.2. Cell Culture - Caco-2 human IECs (ATCC \#HTB-37) were grown in Dulbecco's Modified Eagle Medium (DMEM; \#11965, Gibco-ThermoFisher Scientific) supplemented with $10 \%$ (v/v) fetal bovine serum (FBS; \#F1051, Sigma-Aldrich, St. Louis, MO), $100 \mathrm{U} / \mathrm{mL}$ penicillin and $100 \mu \mathrm{g} / \mathrm{mL}$ streptomycin (\#15140, Gibco), 1 mM sodium pyruvate (\#S8636, Sigma-Aldrich), and 1X MEM Non-Essential Amino Acids (\#11140, Gibco). Cells were maintained in a $37{ }^{\circ} \mathrm{C}$ humidified incubator with $5 \% \mathrm{CO}_{2}$ and were routinely passaged every four days at $~ 50 \%$ confluence using Trypsin-EDTA (0.25\%-0.91 mM; \#25200, Gibco) solution. All experiments were performed using cells from passage 41-45.

2.3. Wound Closure Assays - Caco-2 cells were seeded into Nunclon ${ }^{\mathrm{TM}}$ Delta 96-Well MicroWell plates (\#167008, ThermoFisher Scientific) at a density of $1.5 \times 10^{4}$ cells $/ \mathrm{cm}^{2}$ and were maintained for seven days in complete medium. Under these conditions, cells reached confluence in 5-6 days. On day eight, the monolayers underwent overnight serum starvation in preparation for the wound closure assay. On day nine, circular wounds were made using the WoundMaker tool (Essen BioSciences, Ann Arbor, MI). Wounded monolayers were washed twice with serum-free media to remove cellular debris. The wash media was then replaced with treatment media (HS compounds at various concentrations, or DMSO at 1\% (v/v), diluted in complete medium, 150 $\mu \mathrm{L} /$ well). Plates were placed into the IncuCyte live-cell imaging system (Essen BioSciences) and maintained in culture at $37^{\circ} \mathrm{C}, 5 \% \mathrm{CO}_{2}$ while whole-well phase images were taken once every hour for 72 hours. ImageJ (Schindelin et al, 2012) was used to batch compile overlay masks for images exported from the IncuCyte ZOOM software. Parameters for each step were set based on stacked images from five random wells per experiment, then applied similarly to the entire experiment. Percentage wound closure was fitted to an exponential plateau model $\left[y=y_{m}-\left(y_{m}\right.\right.$ 
$\left.-\mathrm{y}_{0}\right)^{*} \exp ^{-k^{*} \mathrm{x}}$; where $\mathrm{y}_{0}$ is the starting \% wound closure $(0 \%), \mathrm{ym}_{\mathrm{m}}$ is the maximum $\%$ wound closure $(100 \%)$, and $k$ is the rate constant $\left.\left(h^{-1}\right)\right]$.

2.4. EdU Cell Proliferation Assay - Caco-2 cells were seeded into LabTekll 2-well chambered coverglass (\#155380, ThermoFisher Scientific) pre-coated with 0.01\% Poly---lysine (\#P4707, Sigma-Aldrich), at a density of $1.0 \times 10^{4}$ cells $/ \mathrm{cm}^{2}$. On day eight, the monolayers underwent overnight serum starvation in preparation for wounding. Four scratch wounds per well were created on day nine using a sterile P200 pipette tip attached to an aspirator. The wounded monolayers were washed twice with DMEM then replaced with treatment media (containing 100 $\mu \mathrm{M}$ HS38 or $1 \%$ (v/v) DMSO in complete media, $2 \mathrm{~mL} /$ well) for 10 - or 22-hour incubation in a 37 ${ }^{\circ} \mathrm{C}$ humidified incubator with $5 \% \mathrm{CO}_{2}$. The Click-iT EdU Cell Proliferation Kit was used as per the manufacturer's instructions. Post-incubation, wells were washed with $3 \%(w / v)$ BSA then PBS, then counterstained with Hoechst 33342 for 30 minutes. After mounting with ProLong ${ }^{\mathrm{TM}}$ Glass Antifade Mountant (\#P36980, Invitrogen), images were captured using a Nikon A1R laser scanning confocal microscope. One representative image per wound was saved for subsequent analyses. Image analysis was done using the CellProfiler software (McQuin et al, 2018). Briefly, Hoechst stain was used for the identification of individual cells, and the EdU signal was used to mark cells undergoing proliferation. Objects defined by the EdU overlay were required to overlap with objects defined by the Hoechst stain to ensure that all EdU-positive objects were true. To determine the percentage of EdU-positive nuclei, roll-up summation was done on count of EdUpositive and count of nuclei for wounds within a single well.

2.5. Immunofluorescence Microscopy - Caco-2 monolayers were rinsed twice with PBS prior to a 10-minute incubation with 4\% (v/v) PFA. The fixative was removed with two PBS washes. Then, cells were permeabilized with $0.5 \%$ (v/v) Tween-20 PBS for 10 minutes. Tween-20 was washed off with PBS (3X, 5 min/wash). Blocking of non-specific binding was completed with $5 \%(\mathrm{v} / \mathrm{v})$ normal donkey serum in PBS for one hour at room temperature (RT). The blocking solution was replaced by primary antibody for overnight incubation at $4{ }^{\circ} \mathrm{C}$. The YAP (D8H1X) XP rabbit mAb (14074, Cell Signaling), diluted 1:100 in PBS (containing 1\% (w/v) BSA and 0.3\% (v/v) Triton X100) was used to detect endogenous levels of total YAP protein. Cy3-conjugated AffiniPure 
donkey anti-rabbit IgG was used as the secondary antibody and was applied to samples at 1:200 dilution in conjunction with the Phalloidin-iFluor 647 Reagent used at 1:1,000 dilution in PBS with $1 \%(w / v)$ BSA. Prior to room temperature incubation with secondary antibody and phalloidin (one hour), monolayers were washed three times with PBST (PBS containing 0.1\% (v/v) Tween-20). Three more PBST washes followed, after which DAPI $(10 \mu \mathrm{g} / \mathrm{mL})$ was added for a 3-minute-long incubation to mark nuclei. Two final PBS washes were carried out before samples were mounted with ProLong ${ }^{\mathrm{TM}}$ Glass Antifade Mountant. Images were taken using the Nikon A1R laser scanning confocal microscope on $40 \mathrm{X}$ objective (oil) at Nyquist (xy-plane). For image deconvolution, stacks of seven equidistant $(1 \mu \mathrm{m})$ z-planes were evaluated. The Colocalization GUI toolbox for MATLAB (MathWorks, Natick, MA) was used for image and statistical analysis of YAP-F-actin colocalization (Villalta et al, 2011). The Colocalization GUI algorithm generates a colocalization mask for the calculation of Manders coefficients $m 1$ and $m 2$ (Manders et $a l, 1993$ ). The mask represents pixels that display true (i.e., non-random) colocalization in a pair of images. The $m 1$ and $m 2$ parameters represent the percentage of image 1 (YAP) or image 2 (F-actin) intensity that is colocalized with matched pixels on image 2 (F-actin) or image 1 (YAP), respectively. MAPs are the visual representation of the contribution of each pixel to the colocalization coefficients $m 1$ or $m 2$. Two z-slices per stack (of seven equidistant z-planes) were selected for colocalization analysis based on the broad presence of distinct cortical actin belt across the full image.

2.6. Mouse model of dextran sodium sulphate (DSS)-induced colitis - All animal protocols were approved by the Animal Care and Use Committee at the University of Calgary and conform to the guidelines set by the Canadian Council of Animal Care. Experimental UC was induced in nine to 11-weeks old male C57BL/6 mice by the addition of $2.5 \%(\mathrm{w} / \mathrm{v})$ DSS in drinking water for seven days. For recovery, mice were provided regular drinking water for two days post-DSSacclimatization (DSS+2); at which time, animals were euthanized by cervical dislocation after anesthesia by isoflurane inhalation. Body weight was tracked daily then normalized to day one of DSS administration. A disease activity index (DAI) score was estimated based on weight, stool consistency, and blood in feces (Table 1). Macroscopic scoring of dissected colon tissue was performed according to the grading system outlined in Table 2. 


\subsection{Histological Examination of Epithelial Damage and Inflammation - Paraffin-embedded} tissues (distal colon), sectioned at 5- $\mu$ m thickness, were deparaffinized, rehydrated with gradient ethanol, then stained with hematoxylin and eosin (H\&E) for blinded microscopic assessment of colitis severity. The grading system considers the degree of epithelial damage and infiltration of inflammatory cells (Hirota et al, 2011), as well as the percentage of involvement (Table 3).

2.8. Immunohistochemistry - Deparaffinized tissues were rehydrated with gradient ethanol, then subjected to heat-induced antigen retrieval in $10 \mathrm{mM}$ sodium citrate ( $\mathrm{pH} \mathrm{6.0)}$. Sections were subsequently washed with PBST, then blocked with 10\% normal donkey serum in PBS. Overnight incubation was carried out at $4{ }^{\circ} \mathrm{C}$ with anti-Ki-67, anti-DAPK3, or anti-YAP, diluted 1:400 in PBS. The Cy3-conjugated AffiniPure donkey anti-rabbit IgG was the secondary antibody and was applied to samples at 1:200 dilution. DAPI was used at $10 \mu \mathrm{g} / \mathrm{mL}$ to mark nuclei. For sections probed with anti-Ki-67, images were taken with the Olympus FV10i confocal microscope on the $60 \mathrm{X}$ objective (oil). Ki- $67^{+}$positive nuclei was manually counted, then expressed as a percentage of total nuclei per crypt. Between 19-30 well-oriented crypts from 2-3 sections were evaluated per animal. Sample size was 3-8 animals per group. For sections probed with anti-DAPK3, images were taken with the Olympus FV10i confocal microscope using a 60X objective (oil). For sections probed with anti-YAP, images were taken with Nikon A1R laser scanning confocal microscope on the $40 X$ objective (oil). For image deconvolution, stacks of 10 equidistant $(0.5 \mu \mathrm{m}) \mathrm{z}$-planes were evaluated.

2.9. Immunoblotting - Midsections from murine colon were homogenized in lysis buffer ( $20 \mathrm{mM}$ Tris- $\mathrm{HCl}$ (pH 8.0), $100 \mathrm{mM} \mathrm{NaCl}, 0.1 \%$ (w/v) SDS, $0.9 \mathrm{mM}$ EDTA, 0.5\% (v/v) Triton X-100, $7 \mathrm{mM}$ $\mathrm{Na}_{3} \mathrm{VO}_{4}, 50 \mathrm{mM} \mathrm{NaF}$, and cOmplete ${ }^{\mathrm{TM}}$ Protease Inhibitor Cocktail). Homogenates were sonicated for 10 minutes at $4{ }^{\circ} \mathrm{C}$, then centrifuged at $14,000 \mathrm{rpm}$ for 10 minutes. Supernatants were collected, and proteins were resolved by SDS-PAGE (12\%) gel electrophoresis then transferred onto $0.2 \mu \mathrm{m}$ nitrocellulose membranes. Blocking was done with $5 \%(\mathrm{w} / \mathrm{v})$ non-fat milk in TBST, then membranes were incubated overnight in primary antibodies at $4{ }^{\circ} \mathrm{C}$. Immunoreactive proteins were visualized using the ChemiDoc Imaging System (Bio-Rad Laboratories, Hercules, CA). 
2.10. Statistical Analyses - Data are presented as mean \pm SEM, and the statistical analyses were performed with GraphPad Prism 8.3.0 (GraphPad Software, La Jolla, CA). Unless otherwise noted, the Student's unpaired t-test was used to compare between 2 groups; one-way ANOVA with Dunnett's post hoc test or two-way ANOVA followed by Tukey's multiple comparison test was used to assess more than 2 groups. P values $<0.05$ were considered significant.

\section{RESULTS}

\subsection{Caco-2 monolayer wound closure is enhanced with DAPK3 inhibitor treatment.}

As shown in Figure 1A, treatment with HS38 significantly enhanced Caco-2 wound closure. At $36 \mathrm{~h}$ post-wounding, administration of HS38 (100 $\mu \mathrm{M})$ increased the wound closure by $46 \%$ when compared to the DMSO vehicle control (Figure 1B). Because of enhanced wound closure, many wounds treated with HS38 became segmented after the $36 \mathrm{~h}$ time point and created multiple (smaller) wound areas in one single well (data not shown). The presence of segmented wounds obstructed the ability to complete effective data processing and analyses. Consequently, the time frame for monitoring the wound closure was reduced to $36 \mathrm{~h}$. Figure $1 \mathrm{C}$ shows the percentage wound closure over time, overlayed with curves fitted on to an exponential plateau model to evaluate the rate of closure (Arciero \& Swigon, 2013; Jonkman et al, 2014). The wound closure rate constants support the notion that pharmacological inhibition of DAPK3 with HS38 increases the rate of wound closure in a concentration-dependent manner (Figure 1D). Examination of the fitted curves (Figure 1C) suggests that at higher [HS38], the rate of wound closure might not be restrained by the parameters set forth for the modeling exercise (i.e., plateau $\neq 100 \%)$. To investigate further, the first derivatives of the percentage wound closure curves were calculated. As shown in Figure 1E, the derivative for the rate of wound closure decreased over time for the control conditions while the HS38 treatment did not attenuate the rate despite having reached a greater percentage of closure at $36 \mathrm{~h}$. Presumably, DAPK3 inhibition via HS38 interfered with the sensing of chemical and/or mechanical environmental cues that would otherwise inform the collective behaviour of the reparative monolayer.

In addition to DAPK3, HS38 exhibits high potency towards DAPK1 and the structurally related proviral integrations of moloney virus 3 (PIM3) kinase (Table 4; Carlson et al, 2013). To 
differentiate the DAPK3-mediated phenotype from the PIM3-mediated phenotype, parallel experiments were conducted by treating wounded Caco-2 monolayers with HS38, HS56 (more inhibitory activity towards PIM3), or HS94 (less inhibitory activity towards PIM3) (Carlson et al, 2018). As illustrated in Figures 2A and 2B, HS94 yielded a similar phenotype as HS38, whereas HS56 treatment produced an opposite phenotype. That is, monolayers treated with HS56 yielded a reduction in percentage wound closure (21\% decrease vs. DMSO vehicle control), and monolayers treated with HS94 experienced enhanced wound closure (19\% increase vs. DMSO vehicle control) at $36 \mathrm{~h}$. The wound closure of monolayers treated with HS56 plateaued at around $40 \%$. In several independent replicates, wound closure of Caco-2 monolayers treated with HS56 halted at about $36 \mathrm{~h}$ post-wounding and failed to achieve $100 \%$ wound closure (data not shown). The rate constants derived from modeling exhibited the same trend as what was reflected by the $36 \mathrm{~h}$ end-point measurement of percentage wound closure. That is, HS94 yielded a greater rate constant whereas HS56 produced a lower rate constant (Figure 2C). Interestingly, in the early phase of wound closure, treatment with HS56 increased the rate of wound closure (Figure 2D); however, this was not sustained, and a rapid deceleration in wound repair was observed as time advanced.

\subsection{Caco-2 cell proliferation is augmented with application of the DAPK3 inhibitor HS38.}

The closure of epithelial wounds involves epithelial cell proliferation and migration. To examine the effects of HS38 administration and DAPK3 inhibition on cellular proliferation in wounded monolayers, EdU-coupled fluorescence was used to evaluate cell proliferation around wound edges at 12- and 24-hours after wounding. In this case, HS38 treatment did not alter the percentage of EdU-positive cells at 12 hours post-wounding (Figure 3A). However, at 24 hours post-wounding, cell proliferation in HS38-treated monolayers was significantly greater than in the control monolayer (Figure 3B; HS38: 38\% EdU-positive, DMSO: 18\% EdU-positive; p<0.01). This finding suggests that the enhanced rate of wound closure seen with HS38-treated monolayers (Figure 1) was owed, in part, to an augmentation of cell proliferation by DAPK3 inhibition. 
Although the percentage of EdU-positive cells did not change in response to HS38 treatment at the $12 \mathrm{~h}$ time point, an interesting observation was made when EdU intensity levels were transformed from a nominal to an interval scale (Figure $3 \mathrm{C}$ ). When cells in the EdU-positive population were partitioned based on relative intensity, it was apparent that most EdU-positive cells in the HS38-treated monolayers exhibited maximal-intensity (>0.9), whereas the opposite was true for cells in the control monolayer (Figure 3C; EdU-positive cells showing maximalintensity: HS38, 56\%, Control, 16\%; p=0.024). Similar bias was detected for monolayers treated for 24 hours with HS38; among the EdU-positive cells exposed to HS38, 57\% were found to have reached maximum intensity, whereas only $5 \%$ of the EdU-positive cells $(p=0.012)$ in control monolayers achieved maximum intensity (Figure 3C).

\subsection{Treatment of Caco-2 monolayers with HS38 increased colocalization of YAP with F-actin.}

Previous reports have associated DAPK3 expression and/or activity with perturbed cell cycle kinetics (Hu et al, 2020; Ono et al, 2020; Wu et al, 2015) and actomyosin cytoskeletal remodelling (Boosen et al, 2009; Komatsu \& Ikebe, 2004; Nehru et al, 2013). Moreover, mechanical signaling via alterations to the actin cytoskeleton is a critical controller of Yesassociated protein (YAP) (Aragona et al, 2013; Wada et al, 2011). Studies have shown the colocalization of YAP with F-actin under YAP-activating conditions (Lee et al, 2019) as well as reported an association of YAP expression and/or activity with S-phase shortening and promotion of G1/S transition (Cabochette et al, 2015; Cai et al, 2010). These findings, along with a potential regulatory relationship identified for DAPK3 and YAP in colitis-associated dysplasia (Chen \& MacDonald, 2021), provide impetus to complete additional investigations of DAPK3 inhibition on the colocalization of YAP with F-actin.

The colocalization of YAP and F-actin immunofluorescence (Figure 4A) was evaluated at the wound edges of Caco-2 monolayers at 24 hours post-wounding by computation with a colocalization mask algorithm (Villalta et al., 2011). The $m 1$ MAP, providing visual representation of the contribution of each pixel to the colocalization coefficients $m 1$, is displayed in Figure 4B. The $m 1$ coefficient values, which represent the percentage of YAP-positive pixels that are colocalized with matched pixels on the F-actin channel, are summarized in Figure 4C. The $m 1$ 
mean value for HS38-treated monolayers was significantly greater than for the control monolayers $(+0.253 \pm 0.079, p=0.0064)$. Since $m 1$ values represent the percentage of YAPpositive pixels that also display non-random fluorescence in the phalloidin channel, this result suggests that DAPK3 inhibition increased colocalization of YAP with F-actin. Even though the difference in $m 1$ value between treatment types was significant, several control monolayers exhibited similar $m 1$ values as HS38 treated monolayers (Figure 4C). Potentially, the $m 1$ quantification result for the control monolayers included data points that were driven by high, but focused, YAP staining at defined subcellular compartment/components. Qualitative analysis of $m 1$ MAPs generated for HS38-treated and control monolayers supported this hypothesis. As shown in Figure 4B, monolayers treated with HS38 displayed a qualitative difference in dispersion of $m 1$ signal intensity throughout the entire cell cytoplasm, whereas the $m 1$ signal intensity are localized to the cortical actin ring on the cell periphery in the control monolayer. The visual phenotype displayed in Figure 4B is representative of the general trend observed for the two treatment types. One interpretation of these data is that the inhibition of DAPK3 initiated YAP activation via dispersion of YAP from the cell membrane. Continued association of YAP with Factin in the cytoplasm might aid the transport of YAP from cell periphery to the nuclear membrane. It should be noted, however, that YAP immunofluorescence exhibited few instances of nuclear localization in monolayers treated with either HS38 or vehicle (Figure 4A).

\subsection{In vivo HS38 administration increased susceptibility to DSS-induced colitis}

Mice were administered HS38 by s.c. injection and then provided DSS in drinking water (Figure 5A). Mice administered DSS and HS38 showed greater weight loss than their vehiclecontrol littermates ( $p<0.0001$; Figure 5B). Moreover, two of the DSS mice that were co-treated with HS38 had to be removed from the study due to severe weight loss that exceeded the humane endpoint criteria (i.e., weight loss of $>15 \%$ ). While there was no general variation in DAl (disease activity index) over the course of DSS administration, post hoc multiple comparison showed significant HS38-dependent change in DAI at DSS+2 (i.e., seven days of DSS treatment plus two days of recovery in the presence or absence of HS38 treatment; $p=0.039$, Figure 5C). Colon lengths (Figure 5D) and macroscopic scores (Figure 5E) exhibited subtle, but nonsignificant, differences between HS38- and vehicle-treated mice at DSS+2, and histological 
analyses revealed a small but significant increase in colitis severity for the HS38-treated mice, as per measures of epithelial damage and inflammation (Figures 5F, 5G). Taken together, these data suggest that DAPK3 plays a protective role in DSS-induced colitis.

\subsection{Increased DAPK3 in IECS is identified with recovery from DSS-induced injury (DSS+7).}

Immunohistochemistry was used to probe DAPK3 protein localization within the distal colon of mice (Figure 5H). DAPK3 immunoreactivity was observed for epithelial cells in tissue sections dissected from both healthy (H2O) and colitis (DSS) animals. The colonic epithelium of healthy animals was characterized by punctate DAPK3 immunoreactivity most prominently observed in the cytoplasm of IECs at the villus tips and the crypt base columnar cells. Prominent immunoreactivity was observed for the epithelium of colitis animals with cytoplasmic DAPK3 staining. As expected, villous atrophy and other morphological alterations were apparent in colons of DSS-colitis animals, and demonstrable DAPK3 immunoreactivity was detected in the crypts of the damaged epithelium. Colonic crypts were isolated from distal colon tissue (Magness et al, 2013) to further profile DAPK3 in IECs. The epithelial expression of Dapk3 was not impacted by DSS-induced colitis or HS38 treatments (Figure 6A); however, DAPK3 protein abundance was significantly elevated in IECs isolated from animals in the recovery phase following removal of DSS (Figure 6B). Flow cytometry and gating with EpCaM (epithelial), CD31 (endothelial) and CD45 (hematopoietic) confirmed that $>75 \%$ of cells in the cellular analytes were epithelial in nature (Figure 6C). Taken together, these data support the concept that DAPK3 functions as a responding element within IECs during the resolution of experimental colitis.

\subsection{In vivo HS38 administration attenuated IEC proliferation post DSS-induced injury}

To determine the proliferative fraction of IECs in mice, paraffin-embedded distal-colon tissues were probed with antibodies targeting Ki-67 (Figure 7A). Mice given regular drinking water showed no significant differences in IEC proliferation regardless of treatment with HS38 or vehicle (Figure 7B). In these animals, $\mathrm{Ki}-67^{+}$cells were displayed at the crypt base and encompassed $\sim 25 \%$ of total crypt IECs (Figure 7B). In response to DSS-induced injury, the proportion of $\mathrm{Ki}-67^{+}$cells increased to $~ 57 \%$ of total IECs per crypt. In mice recovering from DSS- 
induced injury, HS38 treatment decreased the epithelial distribution of proliferating cells to levels

like those of uninjured animals ( 32\%, Figure 7B). These data indicate that the administration of HS38 impeded the resolution of intestinal injury and attenuated epithelial-specific proliferation after acute colitis induced by DSS.

\subsection{HS38 administration stimulated YAP nuclear accumulation in vivo}

The effects of HS38 treatment on the core Hippo signaling pathway and the cellular localization of YAP was investigated since a change in IEC proliferation, brought about by DAPK3 inhibition and cytoskeletal destabilization, may involve the Hippo pathway (Aragona et al, 2013). Intriguingly, in $>50 \%$ of uninjured animals, YAP protein abundance appeared elevated in response to DAPK3 inhibition (Figure 8A); however, this difference did not reach statistical significance. DAPK3 inhibition was accompanied with decreased pS127-YAP levels (Figure 8B), significantly so in DSS-treated animals but not in control animals. However, there was no significant impact of DAPK3 inhibition on the levels of p397-YAP (Figure 8C). None of the core Hippo regulators showed significant changes in protein abundance upon DAPK3 inhibition regardless of injury status, including MST1, MST2, LATS1 as well as MOB1 (Figure 9A-D). A decrease in pT35-MOB1 was observed with DSS-induced injury; however, no change in this MOB1 phosphorylation was apparent with HS38 administration (Figure 9E).

The phosphorylation of Ser127 specifically primes the binding of YAP to 14-3-3 and leads to its cytoplasmic retention (Zhao et al, 2007). To substantiate the results obtained from pS127YAP immunoblots, paraffin-embedded distal-colon tissues were probed with antibodies targeting total YAP to evaluate its subcellular localization. In animals receiving both DSS and HS38, colonic IECs showed increased nuclear translocation of YAP when compared to animals receiving DSS and vehicle (Figure 10A); this nuclear accumulation of YAP was observed in IECs located at the crypt base and the crypt apex (Figure 10B, insets (iii) and (iv) respectively). These data suggest that HS38 treatment, and hence DAPK3 inhibition, bypassed the canonical Hippo pathway to activate YAP.

\section{DISCUSSION}


Our findings advance DAPK3 as a novel regulator of intestinal epithelial repair and establish a unique linkage between the kinase function of DAPK3 and the Hippo effector YAP within the context of UC. In vitro cell studies revealed increased IEC proliferation that underwrote the enhanced wound closure observed in monolayers treated with small molecule inhibitors of DAPK3. Additionally, DAPK3 inhibition promoted colocalization of YAP with F-actin, which is indicative of YAP activation. In mice recovering from DSS-induced UC, the inhibition of DAPK3 also prompted YAP activation. However, DAPK3 inhibition repressed injury-induced IEC hyperproliferation, which elicited worsening of disease severity in the animal model. While this discrepancy may be the consequence of interspecies differences on the regulation of DAPK3 subcellular localization (Weitzel et al, 2011), similar effects of DAPK3 inhibition on YAP activation, observed in both Caco-2 IECs and mice, suggests that the conflict is more likely caused by the molecular impact of DAPK3 in non-epithelial cell types, such as macrophages.

The essential role of Hippo signaling on repair from acute intestinal injury has been demonstrated in multiple studies. As the downstream effector of the Hippo pathway, the transcriptional regulator YAP has been implicated as an important mediator of mechanotransduction and proliferation during colonic epithelial repair. With regards to the DSS model of colitis, Cai and colleagues showed impaired epithelial regeneration of Yap-deficient colonic crypts (Cai et al, 2010). Moreover, Yui and colleagues found that the colonic epithelium undergoes a YAP-dependent transition to fetal-like state to facilitate repair during recovery (Yui et al, 2018). Mucosal healing is also crucial for tempering the progression of UC (Boal Carvalho et al, 2016), and YAP activity was suggested to promote mucosal regeneration for UC recovery. In this case, IEC-specific YAP ablation in mice increased weight loss and tissue damage with DSSassociated colitis and was shown to impede regeneration of colonic crypts (Cai et al, 2010; Taniguchi et al, 2015).

DAPK3 may regulate YAP-mediated cell proliferation and cell cycle progression via various molecular pathways. For one, DAPK3 may exert control on YAP activity through Wnt signaling, as DAPK3 knockdown was shown to reduce $\beta$-catenin/TCF4 mediated-transcriptional activities (Togi et al., 2011), and Wnt signaling was demonstrated to induce YAP activity during crypt regeneration (Guillermin et al, 2021). However, it should be noted that DAPK3 kinase activity was 
not required for its regulation of Wnt signaling (Togi et al, 2011), and Wnt signaling could induce YAP activity via increased transcription of YAP rather than through post-translational regulation of YAP protein localization (Guillermin et al, 2021). Thus, the impact of DAPK3 on YAP, brought about through HS38 administration, is unlikely to be facilitated via Wnt signaling.

Additionally, DAPK3 may promote YAP activity through mechanical cues, elicited by changes to cell tension that occur with the phosphorylation of myosin regulatory light chain (MLC20). Actomyosin, composed of F-actin and non-muscle myosin II, serves as a central mediator between mechanical cues and Hippo/YAP signaling (Nardone et al, 2017). DAPK3 can directly phosphorylate MLC20 (Komatsu \& Ikebe, 2004; Moffat et al, 2011) and may also influence actomyosin-dependent cellular tension through its inhibition of myosin light chain phosphatase (MLCP) (MacDonald et al, 2001). Merlin/NF2, an upstream regulator of the Hippo pathway, was demonstrated to be a substrate of MLCP (Jin et al, 2006), and recent evidence showed that the knockdown of MYPT1 (i.e., PPP1R12A, the myosin phosphatase-targeting subunit of MLCP) in ovarian cancer cell lines was associated with increased Merlin/NF2 phosphorylation and coincident activation of the Hippo pathway (Munoz-Galvan et al, 2020). As DAPK3 inhibition with HS38 ought to enhance MLCP function, thus strengthening the activation of Merlin/NF2 to reduce YAP activity, the (de)regulation of MLCP function via DAPK3 inhibition does not explain the outcomes observed in the cell studies. However, the substrate preferences of DAPK3 within the locational context of the IEC intracellular environment remain to be described.

In terms of IEC proliferation, no changes were observed between HS38-treatment and vehicle control in mice at baseline. However, in $>50 \%$ of uninjured mice (i.e., mice receiving $\mathrm{H}_{2} \mathrm{O}$ instead of DSS), YAP protein abundance increased in response to administration of HS38. As well, a trend was found towards a reduction in phosphorylation of YAP on S127 in these animals. Given that YAP is largely dispensable in homeostasis, it was not surprising to find a lack of prominent defects in these control animals despite the alteration of YAP protein abundance and YAP activation by HS38. Unexpectedly, however, the hyperproliferative phenotype of Caco-2 cells treated with HS38 was not observed in the DSS-model of animal colitis. Instead, animals treated with HS38 displayed a significant decrease in IEC proliferation. This anti-proliferative effect of 
HS38 on IECs likely played a part in the worsening severity of DSS-induced colitis. Paradoxically, in mice recovering from DSS-induced injuries, pS127-YAP levels decreased significantly in the HS38 treatment group. Further, DAPK3 inhibition stimulated YAP nuclear accumulation in colonic IECs. These data suggest that DAPK3 inhibition prompted YAP activation, which ought to have enhanced IEC regeneration. One plausible explanation for such paradoxical phenotype is that the IEC proliferation in mice recovering from DSS-induced injury was depressed by the functioning of YAP in other cell types.

A recent study suggests that YAP can drive macrophages toward M1 polarization while restricting M2 polarization during UC development (Zhou et al, 2019). While IEC proliferation was not specifically examined, myeloid-specific ablation of YAP could attenuate the severity of DSSinduced colitis; YAP impeded M2 polarization, promoted M1 polarization, and increased production of IL-6 (Zhou et al, 2019). Given that IL-6 signaling can trigger YAP activation via stimulation of gp130-associated Src family kinase Yes (Taniguchi et al, 2015), a positive feedback loop between YAP and IL-6 production by macrophages likely exists. Potentially, DAPK3 inhibition brought about YAP activation in macrophages, which could impair M2 polarization to depress IEC proliferation post-DSS-induced injury. The regulation of macrophage programming by DAPK3 was also demonstrated (Mukhopadhyay et al, 2008); DAPK3 restrained IFN- $\gamma$ induced gene expression in macrophages through its phosphorylation of the ribosomal protein L13a. The phosphorylation of L13a activated the IFN- $\gamma$-activated inhibitor of translation complex to repress translation of inflammatory genes (Mukhopadhyay et al, 2008). Taken together, DAPK3 may contribute an important role in the macrophage resolution of inflammation program and take part in a yet undefined counteracting mechanism that resets the positive feedback loop between YAP and IL6 in macrophages.

Ultimately, a genetic approach will likely be necessary to dissect the independent roles that DAPK1 and DAPK3 play in intestinal epithelial repair and Hippo signaling. However, the current absence of genetic resources precludes the confirmation of results obtained with pharmacologic inhibition of DAPK3 using mouse models. Global Dapk3 knockout is embryonically lethal for mice (Kocher et al, 2015), with similar lethality observed for endothelial-cell specific Dapk3 knockout (Zhang et al, 2019). While inducible-Dapk3 whole-body knockout and smooth-muscle specific 
Dapk3 knockout mice were successfully generated (Zhang et al, 2019), Dapk3 knockout cell lines created with CRISPR-Cas9 gene editing could not be maintained, suggesting an essential role for DAPK3 in cell growth and/or survival (Takahashi et al, 2021).

An advantage of small molecule inhibitors is that they can be titrated to reveal a spectrum of phenotypes. Moreover, the inhibition of enzymatic activity does not necessarily prevent protein-protein interactions. Therefore, the use of small molecule inhibitors presents an opportunity to differentiate between the enzymatic and structural roles of proteins. Several uncommon features in the ATP-binding pocket of DAPK3 underwrite the high selectivity offered by HS38; nevertheless, HS38 still displays high potency towards DAPK1 and the structurally related PIM3 kinase (Carlson et al, 2013). So, it is necessary to consider the off target impacts of DAPK1 and PIM3 on IEC wound healing when utilizing HS38. The PIM3-mediated contribution of HS38 to wound healing was addressed in this study (Figure 2). Parallel in vitro experiments completed by treatment of Caco-2 cells with HS38, HS56 or HS94 facilitated the assignment of observed effects as being DAPK3-centric or PIM3-centric. Unfortunately, with regards to DAPK1, all currently available DAPK3 inhibitors demonstrate comparable potency towards both DAPK1 and DAPK3 (Al-Ghabkari et al, 2016; Carlson et al, 2013; Okamoto et al, 2010). Thus, the crosstalk between DAPK3 and DAPK1 and the potential for overlapping biological functions will need to be assessed in future studies. This may be possible once additional structure-activity relationship (SAR) studies inform the construction of pharmacophores that can differentiate between DAPK3 and DAPK1.

\section{ACKNOWLEDGEMENTS}

This work was supported by a research grant from the Canadian Institutes of Health Research (MOP\#97931 to J.A.M.). H.-M.C. was recipient of CIHR Fredrick Banting and Charles Best Canada and Alberta Graduate Excellence Scholarships.

\section{AUTHOR CONTRIBUTIONS}

H.-M.C. completed the data analysis, prepared figures, and wrote the manuscript. D.A.C synthesized the DAPK3 inhibitor compounds HS-38, HS-94 and HS-56. T.A.J.H. coordinated inhibitor compound production and made intellectual contributions to the project. J.A.M. 
conceived and coordinated the study, assisted with experimental design, wrote the manuscript, provided trainee supervision, and made intellectual contributions to the project. All authors reviewed the results and approved the final version of the manuscript.

\section{AUTHORS' DECLARATION OF INTERESTS STATEMENT}

J.A.M. is cofounder and has an equity position in Arch Biopartners Inc. T.A.J.H is founder and has an equity position in Eydis Bio Inc. All other authors declare no conflicts of interest. 


\section{TABLES}

Table 1. Criteria for the scoring of disease activity index (DAI) for mice subjected to the DSSassociated colitis model.

\begin{tabular}{|c|c|c|c|c|}
\hline \multirow{2}{*}{ Parameter } & \multicolumn{4}{|c|}{ Score } \\
\cline { 2 - 5 } & $\mathbf{0}$ & $\mathbf{1}$ & $\mathbf{2}$ & $\mathbf{3}$ \\
\hline Weight Change & $<=5 \%$ & $>5 \%$ & $>10 \%$ & $>15 \%$ \\
\hline Stool Consistency & Normal & Loose Stool & Diarrhea & \\
\hline Blood in Stool & Normal & Slight & Gross & \\
\hline
\end{tabular}

Table 2. Criteria for the macroscopic scoring of mouse colon tissue dissected from the DSSassociated colitis model.

\begin{tabular}{|c|c|c|c|c|}
\hline \multirow{2}{*}{ Parameter } & \multicolumn{4}{|c|}{ Score } \\
\cline { 2 - 5 } & $\mathbf{0}$ & $\mathbf{1}$ & $\mathbf{2}$ & $\mathbf{3}$ \\
\hline $\begin{array}{c}\text { Colon } \\
\text { Shortening }\end{array}$ & $<5 \%$ & $6-15 \%$ & $16-30 \%$ & $>30 \%$ \\
\hline Colonic Edema & Normal & $>=1 \mathrm{~cm}$ & $>=3 \mathrm{~cm}$ & $>=5 \mathrm{~cm}$ \\
\hline Adhesion & None & Minor & Major & \\
\hline Inflammation & Normal & $\begin{array}{c}\text { Localized } \\
\text { Hyperemia }\end{array}$ & $\begin{array}{c}\text { Ulceration w/o } \\
\text { Hyperemia }\end{array}$ & $\begin{array}{c}\text { Ulceration with } \\
\text { Inflammation }\end{array}$ \\
\hline
\end{tabular}


Table 3. Criteria for the histological scoring of epithelial damage and inflammation in distal colons isolated from the DSS-associated colitis model.

\begin{tabular}{|c|c|c|c|c|c|}
\hline \multirow{2}{*}{ Parameter } & \multicolumn{5}{|c|}{ Score } \\
\cline { 2 - 6 } $\begin{array}{c}\text { Epithelial } \\
\text { Damage }\end{array}$ & $\mathbf{0}$ & $\mathbf{1}$ & $\mathbf{2}$ & $\mathbf{3}$ & $\mathbf{4}$ \\
\hline $\begin{array}{c}\text { \% Architectural } \\
\text { Change }\end{array}$ & $0 \%$ & $\begin{array}{c}\text { Vacuolation/ } \\
\text { Bleeding }\end{array}$ & $\begin{array}{c}\text { Loss of } \\
\text { Epithelium }\end{array}$ & $\begin{array}{c}\text { Complete Loss } \\
\text { of Crypt } \\
\text { Architecture }\end{array}$ & $>60 \%$ \\
\hline $\begin{array}{c}\text { Inflammation } \\
\text { Normal }\end{array}$ & $\begin{array}{c}\text { Inflammatory } \\
\text { Cells in the } \\
\text { Lamina Propria }\end{array}$ & $\begin{array}{c}\text { Inflammatory } \\
\text { Cells in the } \\
\text { Submucosa }\end{array}$ & $\begin{array}{c}\text { Inflammatory } \\
\text { Cell Mass }\end{array}$ & $\begin{array}{c}\text { Transmural } \\
\text { Inflammation }\end{array}$ \\
\hline Inflammation & $0 \%$ & $1-25 \%$ & $26-50 \%$ & $51-75 \%$ & $>75 \%$ \\
\hline
\end{tabular}

Table 4. Inhibition constants for the HS compounds.

\begin{tabular}{rccc} 
& \multicolumn{3}{c}{$\boldsymbol{K}_{\mathbf{i}}(\mu \mathrm{M})$} \\
\cline { 2 - 4 } DAPK3 & HS38 & HS56 & HS94 \\
\cline { 2 - 4 } PIM3 & 0.260 & 0.315 & 0.126 \\
\cline { 2 - 4 } & 0.208 & 0.072 & 2.50 \\
\hline
\end{tabular}

Data extracted from Carlson et al., 2018. 


\section{FIGURE LEGENDS}

Figure 1. DAPK3 inhibition with HS38 in vitro increased Caco-2 wound closure in a concentration-dependent manner. Circular wounds were made on Caco-2 monolayers, and the size of wound areas was measured once per hour as the monolayers healed. Representative images (A) are shown for vehicle (DMSO) and HS38 (100 $\mu \mathrm{M})$ treatments at the $36 \mathrm{~h}$ time point. The images are representative of three independent experiments. Scale bars $=800 \mu \mathrm{m}$. The percent wound closure at $36 \mathrm{~h}$ relative to the initial wound size (B), the percentage wound closure over time with data plotted at $3 \mathrm{~h}$ intervals $(\mathbf{C})$, the rate constants $\left(k, \mathrm{~h}^{-1}\right)$ derived by fitting the percent wound closure curve to an exponential plateau model (D), and the first derivative $(d \mathrm{WC})$ of the percent wound closure curve (E) are provided for increasing [HS38] $(1,5,25$, or 100 $\mu \mathrm{M})$. One-way ANOVA with Dunnett's post hoc test comparing the five treatment groups (vehicle and HS38 at various concentrations) indicate significant difference among means, ${ }^{*} p<0.05$. Error bars represent \pm SEM.

Figure 2. In vitro wound closure effects obtained with HS38 can be ascribed to DAPK3 inhibition. Circular wounds were made on Caco-2 monolayers, and the percent wound closure over time was plotted at $3 \mathrm{~h}$ intervals (A). The percent wound closure after $36 \mathrm{~h}$ was compared for monolayers treated with HS38, HS56 or HS94 (all at $100 \mu \mathrm{M}$ ). Error bars represent \pm SEM. (B), the rate constants $\left(k, \mathrm{~h}^{-1}\right)$ derived by fitting the \% wound closure curve to an exponential plateau model $(C)$, and the first derivative $(d \mathrm{WC})$ of the percent wound closure curve (D) are provided. Error bars represent $95 \% \mathrm{Cl}$. Figures are representative of three independent experiments.

Figure 3. DAPK3 inhibition alters Caco-2 proliferation and cell cycle progression during in vitro wound closure. Circular wounds were made on Caco-2 monolayers. EdU-labeled proliferation was assessed after treatment with HS38 at $100 \mu \mathrm{M}$ for 12 hours (A) or 24 hours (B). In (C), the distribution of EdU-coupled fluorescence intensity was determined after 12 hours or 24 hours of vehicle (DMSO, 1\%) or HS38 $(100 \mu \mathrm{M})$ treatment. Statistical significance was determined via unpaired Student's t-test; * $p<0.05,{ }^{* *} p<0.01$. Error bars represent \pm SEM for $n=3-4$ independent experiments. Scale bars $=300 \mu \mathrm{m}$.

Figure 4. In vitro DAPK3 inhibition increased YAP colocalization with F-actin. Immunofluorescence images (A) of Caco-2 monolayers were taken with a laser scanning confocal microscope at Nyquist (xy-plane). For image deconvolution, stacks of seven equidistant (1 $\mu \mathrm{m}) \mathrm{z}$ planes were evaluated. In (B), $m 1$ MAPs of representative images from the HS38-treated and control groups. Jet color bar: contribution of each pixel to the $\mathrm{m} 1$ coefficient. Scale bars $=300$ $\mu \mathrm{m}$. In (C), comparison of $m 1$ coefficient values between HS38-treated (100 $\mu \mathrm{M})$ and vehicle control (DMSO, 1\%) monolayers showed significant increase in colocalization of YAP and phalloidin immunofluorescence. Datapoints represent z-slices analyzed for colocalization; error bars represent $\pm S E M, n=3-4$ independent experiments.

Figure 5. DAPK inhibition with HS38 in vivo increased susceptibility to DSS-induced colitis. Mice were subjected to experimental colitis (A) by providing $2.5 \%$ DSS in drinking water ad libidum for 7 days while receiving daily injections of HS38 $(500 \mu \mathrm{g} / \mathrm{kg})$ or vehicle (DMSO). Animals were then 
sacrificed after two days recovery on normal water (DSS+2). The percentage weight change (B) and disease activity index, DAI (C) were monitored over the 8 days when mice were co-treated with DSS and HS38 $(n=12)$ or vehicle control $(n=10)$. Statistical significance was determined via multiple comparison analysis after 2 way-ANOVA with the Šídák correction method; ** $p<0.01$, $* * * p<0.001$. Colons were dissected (D) and macroscopic scores (E) were determined for HS38and vehicle-treated mice at DSS+2. Histological scoring (F) was completed using H\&E-stained transverse sections (G) of colons from vehicle- and HS38-treated mice; scale bars (black) = 300 $\mu \mathrm{m}$, scale bars (yellow) $=50 \mu \mathrm{m}$. Statistical significance was determined via unpaired Student's ttest; $* p<0.05$. Error bars represent \pm SEM. DAPK3 immunoreactivity was identified in the intestinal epithelium of mice $(\mathbf{H})$. Cross-sections of the distal colon were fixed and probed with anti-DAPK3 and counterstained with DAPI. Scale bars, $50 \mu \mathrm{m}$.

Figure 6. Increased DAPK3 abundance is identified in colonic IECs following recovery from DSSinduced colitis. Mice were subjected to experimental colitis by providing $2.5 \%$ DSS in drinking water while receiving HS38 or vehicle (DMSO). Animals were sacrificed after seven days recovery on normal water (DSS+7). Colonic crypts were isolated, then cell lysates were prepared and subjected to qPCR for quantitation of DAPK3 expression (A) or immunoblot analysis for DAPK3 protein abundance (B). Flow cytometry was used to assess the proportion of IECs recovered following isolation of colonic crypts (C). Gating on epithelial cell adhesion molecule (EpCAM) ${ }^{+}$and $\mathrm{CD} 45^{+} / \mathrm{CD} 31^{+}$were used to distinguish IECs from hematopoietic and endothelial cell populations.

Figure 7. DAPK inhibition attenuated colonic IEC proliferation following DSS-induced injury. (A) Representative Ki-67 staining of the colon of HS38-treated and vehicle control mice is provided. Scale bars $=50 \mu \mathrm{m}$. (B) IEC proliferation was quantified in the colon and is provided as the percentage of $\mathrm{Ki}-67^{+}$cells related to the total $\mathrm{DAPI}^{+}$cells per crypt. Statistical significance was determined by 2-way ANOVA with Tukey's post hoc multiple comparisons test $* * p<0.01, * * *$ $p<0.001 ; n=3-8$ animals. Error bars represent \pm SEM.

Figure 8. DAPK3 inhibition was associated with a decrease in pYAP-S127 phosphorylation following DSS-induced injury. Tissue lysates obtained from mouse colon midsections were immunoblotted for YAP (A), pS127-YAP (B), and pS397-YAP (C). GAPDH was used as loading control for YAP whereas the pan-YAP signals were used to normalize the pS127-YAP and pS397YAP levels. Error bars represent \pm SEM, $n=5-7$. Statistical significance between vehicle and HS38 treatments was determined via unpaired Student's t-test, * $\mathrm{p}<0.05$.

Figure 9. Core Hippo pathway regulators display insignificant changes in protein abundance upon DAPK3 inhibition. Lysates obtained from mice colon midsections were immunoblotted for core regulators of the Hippo pathway, including (A) mammalian Sterile 20-like kinases 1 and 2, MST1/2; (B); large tumor suppressor 1 kinase, LATS1, as well as MOB kinase activator 1, MOB1 (C) and its regulatory T35 phosphorylation site (D). GAPDH was used as a loading control, but pan-MOB1 was used to normalize the pT35-MOB1 levels. The results represent the mean normalized protein abundance. Error bars represent $\pm S E M, n=5-7$. Statistical significance was determined via unpaired Student's t-test, $* * P<0.01$. 
bioRxiv preprint doi: https://doi.org/10.1101/2021.12.03.471118; this version posted December 3, 2021. The copyright holder for this preprint (which was not certified by peer review) is the author/funder, who has granted bioRxiv a license to display the preprint in perpetuity. It is made available under aCC-BY-NC-ND 4.0 International license.

Figure 10. DAPK3 inhibition stimulated YAP nuclear accumulation in colonic IECs following DSSinduced injury. Distal-colon tissue sections obtained from mice treated with DSS + DMSO (A) or DSS + HS38 (B) were immunostained for YAP (yellow) and nuclei (DAPI, blue). White arrowheads indicate nuclear accumulation of YAP. Scale bars $=100 \mu \mathrm{m} / 20 \mu \mathrm{m}$ (inset). 


\section{REFERENCES}

Al-Ghabkari A, Deng JT, McDonald PC, Dedhar S, Alshehri M, Walsh MP, MacDonald JA (2016) A novel inhibitory effect of oxazol-5-one compounds on ROCKII signaling in human coronary artery vascular smooth muscle cells. Sci Rep 6: 32118

Aragona M, Panciera T, Manfrin A, Giulitti S, Michielin F, Elvassore N, Dupont S, Piccolo S (2013) A mechanical checkpoint controls multicellular growth through YAP/TAZ regulation by actinprocessing factors. Cell 154: 1047-1059

Arciero J, Swigon D (2013) Equation-based models of wound healing and collective cell migration. In: Complex Systems and Computational Biology Approaches to Acute Inflammation, Vodovotz Y. A.G. (ed.) pp. 185-207. Springer: New York, NY

Boal Carvalho P, Dias de Castro F, Rosa B, Moreira MJ, Cotter J (2016) Mucosal Healing in Ulcerative Colitis--When Zero is Better. J Crohns Colitis 10: 20-25

Boosen M, Vetterkind S, Kubicek J, Scheidtmann KH, Illenberger S, Preuss U (2009) Par-4 is an essential downstream target of DAP-like kinase (Dlk) in Dlk/Par-4-mediated apoptosis. Mol Biol Cell 20: 4010-4020

Buning C, Geissler N, Prager M, Sturm A, Baumgart DC, Buttner J, Buhner S, Haas V, Lochs H (2012) Increased small intestinal permeability in ulcerative colitis: rather genetic than environmental and a risk factor for extensive disease? Inflamm Bowel Dis 18: 1932-1939

Cabochette P, Vega-Lopez G, Bitard J, Parain K, Chemouny R, Masson C, Borday C, Hedderich M, Henningfeld KA, Locker $M$ et al (2015) YAP controls retinal stem cell DNA replication timing and genomic stability. Elife 4: e08488

Cai J, Zhang N, Zheng Y, de Wilde RF, Maitra A, Pan D (2010) The Hippo signaling pathway restricts the oncogenic potential of an intestinal regeneration program. Genes Dev 24: 23832388

Carlson DA, Franke AS, Weitzel DH, Speer BL, Hughes PF, Hagerty L, Fortner CN, Veal JM, Barta TE, Zieba BJ et al (2013) Fluorescence linked enzyme chemoproteomic strategy for discovery of a potent and selective DAPK1 and ZIPK inhibitor. ACS Chem Biol 8: 2715-2723

Carlson DA, Singer MR, Sutherland C, Redondo C, Alexander LT, Hughes PF, Knapp S, Gurley SB, Sparks MA, MacDonald JA et al (2018) Targeting Pim Kinases and DAPK3 to Control Hypertension. Cell Chem Biol 25: 1195-1207 e1132

Chang J, Leong RW, Wasinger VC, Ip M, Yang M, Phan TG (2017) Impaired Intestinal Permeability Contributes to Ongoing Bowel Symptoms in Patients With Inflammatory Bowel Disease and Mucosal Healing. Gastroenterology 153: 723-731 e721 
Chen H-M, MacDonald JA (2021) Molecular network analyses implicate death-associated protein kinase 3 (DAPK3) as a key factor in colitis-associated dysplasia progression. MedRvxiv doi: https://doi.org/10.1101/2021.09.21.21263916 [PREPRINT]

Del Zotto B, Mumolo G, Pronio AM, Montesani C, Tersigni R, Boirivant M (2003) TGF-beta1 production in inflammatory bowel disease: differing production patterns in Crohn's disease and ulcerative colitis. Clin Exp Immunol 134: 120-126

Deng F, Peng L, Li Z, Tan G, Liang E, Chen S, Zhao X, Zhi F (2018) YAP triggers the Wnt/betacatenin signalling pathway and promotes enterocyte self-renewal, regeneration and tumorigenesis after DSS-induced injury. Cell Death Dis 9: 153

Gruber R, Panayiotou R, Nye E, Spencer-Dene B, Stamp G, Behrens A (2016) YAP1 and TAZ Control Pancreatic Cancer Initiation in Mice by Direct Up-regulation of JAK-STAT3 Signaling. Gastroenterology 151: 526-539

Guillermin O, Angelis N, Sidor CM, Ridgway R, Baulies A, Kucharska A, Antas P, Rose MR, Cordero J, Sansom O et al (2021) Wnt and Src signals converge on YAP-TEAD to drive intestinal regeneration. $E M B O$ J 40: e105770

Haberman Y, Karns R, Dexheimer PJ, Schirmer M, Somekh J, Jurickova I, Braun T, Novak E, Bauman L, Collins MH et al (2019) Ulcerative colitis mucosal transcriptomes reveal mitochondriopathy and personalized mechanisms underlying disease severity and treatment response. Nat Commun 10: 38

Hageman JH, Heinz MC, Kretzschmar K, van der Vaart J, Clevers H, Snippert HJG (2020) Intestinal regeneration: Regulation by the microenvironment. Dev Cell 54: 435-446

Hirota SA, Ng J, Lueng A, Khajah M, Parhar K, Li Y, Lam V, Potentier MS, Ng K, Bawa M et al (2011) NLRP3 inflammasome plays a key role in the regulation of intestinal homeostasis. Inflamm Bowel Dis 17: 1359-1372

Howe KL, Reardon C, Wang A, Nazli A, McKay DM (2005) Transforming growth factor-beta regulation of epithelial tight junction proteins enhances barrier function and blocks enterohemorrhagic Escherichia coli 0157:H7-induced increased permeability. Am J Pathol 167: 1587-1597

Hu H, Yin JH, Shao DD, L LW, He F, Huang XX, Guo HL, Xiang XN, Zhu SS, Zhang PH et al (2020) The phosphorylation of hCDC14A modulated by ZIPK regulates autophagy of murine pancreatic islet beta-TC3 cells upon glucose stimulation. Eur Rev Med Pharmacol Sci 24: 10028-10035

Issenman RM, Jenkins RT, Radoja C (1993) Intestinal permeability compared in pediatric and adult patients with inflammatory bowel disease. Clin Invest Med 16: 187-196 
Jin H, Sperka T, Herrlich P, Morrison H (2006) Tumorigenic transformation by CPI-17 through inhibition of a merlin phosphatase. Nature 442: 576-579

Jonkman JE, Cathcart JA, Xu F, Bartolini ME, Amon JE, Stevens KM, Colarusso P (2014) An introduction to the wound healing assay using live-cell microscopy. Cell Adh Migr 8: 440-451

Kagnoff MF (2014) The intestinal epithelium is an integral component of a communications network. J Clin Invest 124: 2841-2843

Koch S, Nusrat A (2012) The life and death of epithelia during inflammation: lessons learned from the gut. Annu Rev Pathol 7: 35-60

Kocher BA, White LS, Piwnica-Worms D (2015) DAPK3 suppresses acini morphogenesis and is required for mouse development. Mol Cancer Res 13: 358-367

Komatsu S, Ikebe M (2004) ZIP kinase is responsible for the phosphorylation of myosin II and necessary for cell motility in mammalian fibroblasts. J Cell Biol 165: 243-254

Lee JY, Dominguez AA, Nam S, Stowers RS, Qi LS, Chaudhuri O (2019) Identification of cell context-dependent YAP-associated proteins reveals beta1 and beta4 integrin mediate YAP translocation independently of cell spreading. Sci Rep 9: 17188

Leoni G, Neumann PA, Sumagin R, Denning TL, Nusrat A (2015) Wound repair: role of immuneepithelial interactions. Mucosal Immunol 8: 959-968

Li GM, Li L, Li MQ, Chen X, Su Q, Deng ZJ, Liu HB, Li B, Zhang WH, Jia YX et al (2021) DAPK3 inhibits gastric cancer progression via activation of ULK1-dependent autophagy. Cell Death Differ 28: 952-967

Li J, Deng Z, Wang Z, Wang D, Zhang L, Su Q, Lai Y, Li B, Luo Z, Chen X et al (2015) Zipperinteracting protein kinase promotes epithelial-mesenchymal transition, invasion and metastasis through AKT and NF-kB signaling and is associated with metastasis and poor prognosis in gastric cancer patients. Oncotarget 6: 8323-8338

Luissint AC, Parkos CA, Nusrat A (2016) Inflammation and the intestinal barrier: Leukocyteepithelial cell interactions, cell junction remodeling, and mucosal repair. Gastroenterology 151: 616-632.

MacDonald JA, Borman MA, Muranyi A, Somlyo AV, Hartshorne DJ, Haystead TA (2001) Identification of the endogenous smooth muscle myosin phosphatase-associated kinase. Proc Natl Acad Sci U S A 98: 2419-2424

Magness ST, Puthoff BJ, Crissey MA, Dunn J, Henning SJ, Houchen C, Kaddis JS, Kuo CJ, Li L, Lynch J et al (2013) A multicenter study to standardize reporting and analyses of fluorescence- 
activated cell-sorted murine intestinal epithelial cells. Am J Physiol Gastrointest Liver Physiol 305: G542-G551

Manders EMM, Verbeek FJ, Aten JA (1993) Measurement of co-localization of objects in dualcolour confocal images. J Microsc 169: 375-382

McQuin C, Goodman A, Chernyshev V, Kamentsky L, Cimini BA, Karhohs KW, Doan M, Ding L, Rafelski SM, Thirstrup D et al (2018) CellProfiler 3.0: Next-generation image processing for biology. PLoS Biol 16: e2005970

Miyoshi H, Ajima R, Luo CT, Yamaguchi TP, Stappenbeck TS (2012) Wnt5a potentiates TGF-beta signaling to promote colonic crypt regeneration after tissue injury. Science 338: 108-113

Moffat LD, Brown SB, Grassie ME, Ulke-Lemee A, Williamson LM, Walsh MP, MacDonald JA (2011) Chemical genetics of zipper-interacting protein kinase reveal myosin light chain as a bona fide substrate in permeabilized arterial smooth muscle. J Biol Chem 286: 36978-36991

Monteleone G, Mann J, Monteleone I, Vavassori P, Bremner R, Fantini M, Del Vecchio Blanco G, Tersigni R, Alessandroni L, Mann D et al (2004) A failure of transforming growth factor-beta1 negative regulation maintains sustained NF-kappaB activation in gut inflammation. $J$ Biol Chem 279: 3925-3932

Mukhopadhyay R, Ray PS, Arif A, Brady AK, Kinter M, Fox PL (2008) DAPK-ZIPK-L13a axis constitutes a negative-feedback module regulating inflammatory gene expression. $\mathrm{Mol} \mathrm{Cell} \mathrm{32:}$ 371-382

Munoz-Galvan S, Felipe-Abrio B, Verdugo-Sivianes EM, Perez M, Jimenez-Garcia MP, SuarezMartinez E, Estevez-Garcia P, Carnero A (2020) Downregulation of MYPT1 increases tumor resistance in ovarian cancer by targeting the Hippo pathway and increasing the stemness. Mol Cancer 19: 7

Nardone G, Oliver-De La Cruz J, Vrbsky J, Martini C, Pribyl J, Skladal P, PesI M, Caluori G, Pagliari $\mathrm{S}$, Martino $\mathrm{F}$ et al (2017) YAP regulates cell mechanics by controlling focal adhesion assembly. Nat Commun 8: 15321

Nehru V, Almeida FN, Aspenstrom P (2013) Interaction of RhoD and ZIP kinase modulates actin filament assembly and focal adhesion dynamics. Biochem Biophys Res Commun 433: 163-169

Nguyen PM, Putoczki TL, Ernst M (2015) STAT3-Activating Cytokines: A Therapeutic Opportunity for Inflammatory Bowel Disease? J Interferon Cytokine Res 35: 340-350

Nigdelioglu R, Hamanaka RB, Meliton AY, O'Leary E, Witt L, Cho T, Sun K, Bonham C, Wu D, Woods PS et al (2016) Transforming Growth Factor (TGF)-beta Promotes de Novo Serine Synthesis for Collagen Production. J Biol Chem 291: 27239-27251 
Nterma P, Panopoulou E, Papadaki-Petrou E, Assimakopoulou M (2020) Immunohistochemical Profile of Tumor Suppressor Proteins RASSF1A and LATS1/2 in Relation to p73 and YAP Expression, of Human Inflammatory Bowel Disease and Normal Intestine. Pathol Oncol Res 26: 567-574

Okamoto M, Takayama K, Shimizu T, Muroya A, Furuya T (2010) Structure-activity relationship of novel DAPK inhibitors identified by structure-based virtual screening. Bioorg Med Chem 18: 2728-2734

Ono T, Terada F, Okumura M, Chihara T, Hamao K (2020) Impairment of cytokinesis by cancerassociated DAPK3 mutations. Biochem Biophys Res Commun 533: 1095-1101

Owen KA, Abshire MY, Tilghman RW, Casanova JE, Bouton AH (2011) FAK regulates intestinal epithelial cell survival and proliferation during mucosal wound healing. PLoS One 6: e23123

Park HW, Kim YC, Yu B, Moroishi T, Mo JS, Plouffe SW, Meng Z, Lin KC, Yu FX, Alexander CM et al (2015) Alternative Wnt Signaling Activates YAP/TAZ. Cell 162: 780-794

Pastorelli L, De Salvo C, Mercado JR, Vecchi M, Pizarro TT (2013) Central role of the gut epithelial barrier in the pathogenesis of chronic intestinal inflammation: lessons learned from animal models and human genetics. Front Immunol 4: 280

Peterson LW, Artis D (2014) Intestinal epithelial cells: regulators of barrier function and immune homeostasis. Nat Rev Immunol 14: 141-153

Piccolo S, Dupont S, Cordenonsi M (2014) The biology of YAP/TAZ: hippo signaling and beyond. Physiol Rev 94: 1287-1312

Qin Z, Xia W, Fisher GJ, Voorhees JJ, Quan T (2018) YAP/TAZ regulates TGF-beta/Smad3 signaling by induction of Smad7 via AP-1 in human skin dermal fibroblasts. Cell Commun Signal 16: 18

Sanchez de Medina F, Romero-Calvo I, Mascaraque C, Martinez-Augustin O (2014) Intestinal inflammation and mucosal barrier function. Inflamm Bowel Dis 20: 2394-2404

Sato A, Kayama H, Shojima K, Matsumoto S, Koyama H, Minami Y, Nojima S, Morii E, Honda H, Takeda K et al (2015) The Wnt5a-Ror2 axis promotes the signaling circuit between interleukin12 and interferon-gamma in colitis. Sci Rep 5: 10536

Schindelin J, Arganda-Carreras I, Frise E, Kaynig V, Longair M, Pietzsch T, Preibisch S, Rueden C, Saalfeld S, Schmid B et al (2012) Fiji: an open-source platform for biological-image analysis. Nat Methods 9: 676-682 
Strober W, Fuss IJ (2011) Proinflammatory cytokines in the pathogenesis of inflammatory bowel diseases. Gastroenterology 140: 1756-1767

Takahashi M, Lio CJ, Campeau A, Steger M, Ay F, Mann M, Gonzalez DJ, Jain M, Sharma S (2021) The tumor suppressor kinase DAPK3 drives tumor-intrinsic immunity through the STING-IFNbeta pathway. Nat Immunol 22: 485-496

Taniguchi K, Wu LW, Grivennikov SI, de Jong PR, Lian I, Yu FX, Wang K, Ho SB, Boland BS, Chang JT et al (2015) A gp130-Src-YAP module links inflammation to epithelial regeneration. Nature 519: $57-62$

Togi S, Ikeda O, Kamitani S, Nakasuji M, Sekine Y, Muromoto R, Nanbo A, Oritani K, Kawai T, Akira S et al (2011) Zipper-interacting protein kinase (ZIPK) modulates canonical Wnt/betacatenin signaling through interaction with Nemo-like kinase and T-cell factor 4 (NLK/TCF4). J Biol Chem 286: 19170-19177

Villalta JI, Galli S, lacaruso MF, Antico Arciuch VG, Poderoso JJ, Jares-Erijman EA, Pietrasanta LI (2011) New algorithm to determine true colocalization in combination with image restoration and time-lapse confocal microscopy to MAP kinases in mitochondria. PLoS One 6: e19031

Wada K, Itoga K, Okano T, Yonemura S, Sasaki H (2011) Hippo pathway regulation by cell morphology and stress fibers. Development 138: 3907-3914

Weitzel DH, Chambers J, Haystead TA (2011) Phosphorylation-dependent control of ZIPK nuclear import is species specific. Cell Signal 23: 297-303

Wu W, Hu H, Ye Z, Leong M, He M, Li Q, Hu R, Zhang S (2015) Zipper-interacting protein kinase interacts with human cell division cycle 14A phosphatase. Mol Med Rep 11: 2775-2780

Xie Z, Wang Y, Yang G, Han J, Zhu L, Li L, Zhang S (2021) The role of the Hippo pathway in the pathogenesis of inflammatory bowel disease. Cell Death Dis 12: 79

Yui S, Azzolin L, Maimets M, Pedersen MT, Fordham RP, Hansen SL, Larsen HL, Guiu J, Alves MRP, Rundsten CF et al (2018) YAP/TAZ-Dependent Reprogramming of Colonic Epithelium Links ECM Remodeling to Tissue Regeneration. Cell Stem Cell 22: 35-49 e37

Zhang Y, Zhang C, Zhang H, Zeng W, Li S, Chen C, Song X, Sun J, Sun Z, Cui C et al (2019) ZIPK mediates endothelial cell contraction through myosin light chain phosphorylation and is required for ischemic-reperfusion injury. FASEB J 33: 9062-9074

Zhao B, Wei X, Li W, Udan RS, Yang Q, Kim J, Xie J, Ikenoue T, Yu J, Li L et al (2007) Inactivation of YAP oncoprotein by the Hippo pathway is involved in cell contact inhibition and tissue growth control. Genes Dev 21: 2747-2761 
bioRxiv preprint doi: https://doi.org/10.1101/2021.12 03.471118. this version posted December 3, 2021. The copyright holder for this preprint (which was not certified by peer review) is the author/funder, who has granted bioRxiv a license to display the preprint in perpetuity. It is made available under aCC-BY-NC-ND 4.0 International license.

Zhou X, Li W, Wang S, Zhang P, Wang Q, Xiao J, Zhang C, Zheng X, Xu X, Xue S et al (2019) YAP Aggravates Inflammatory Bowel Disease by Regulating M1/M2 Macrophage Polarization and Gut Microbial Homeostasis. Cell Rep 27: 1176-1189 e1175 


\section{FIGURE 1}

A
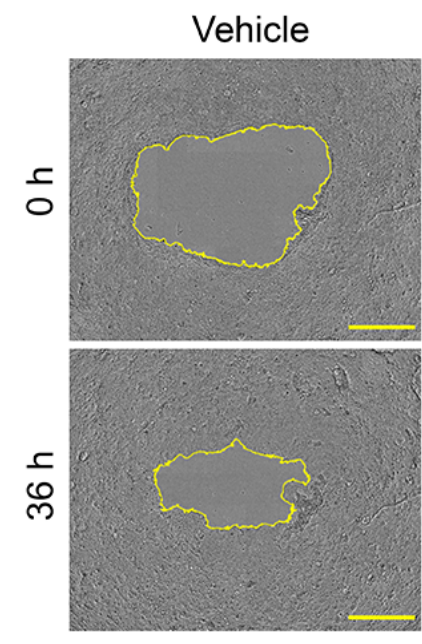

C

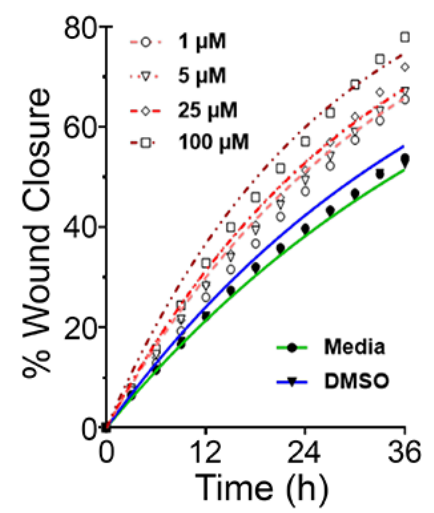

B
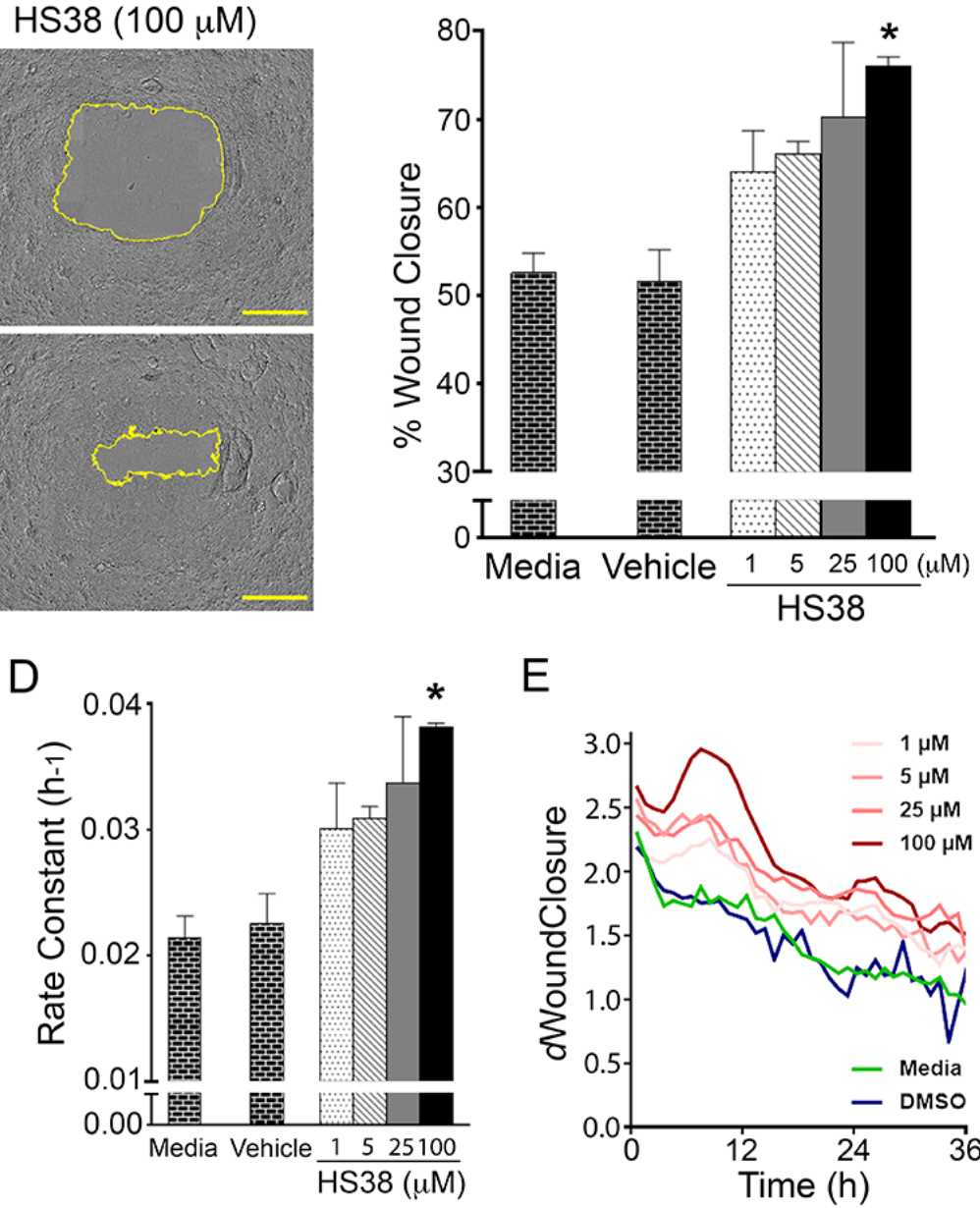

$\mathrm{E}$

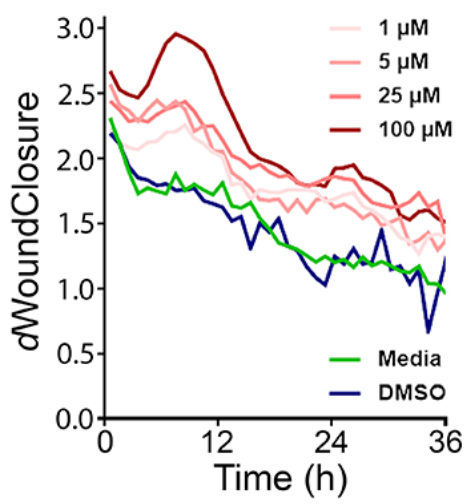


FIGURE 2

A

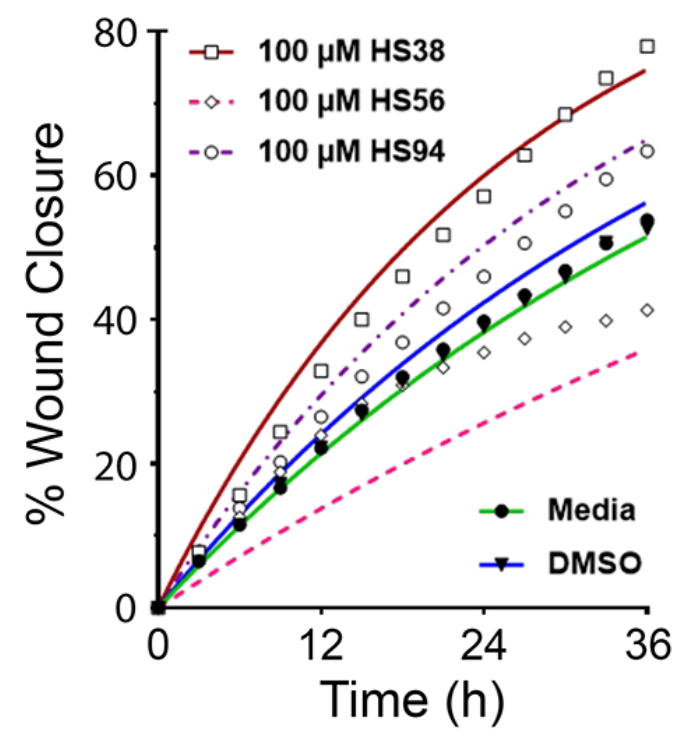

C

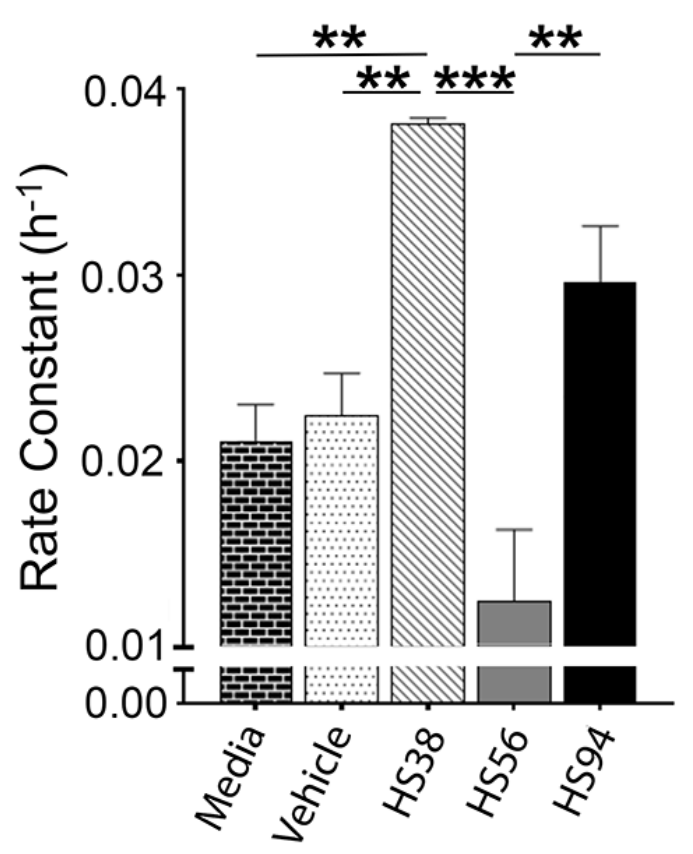

B

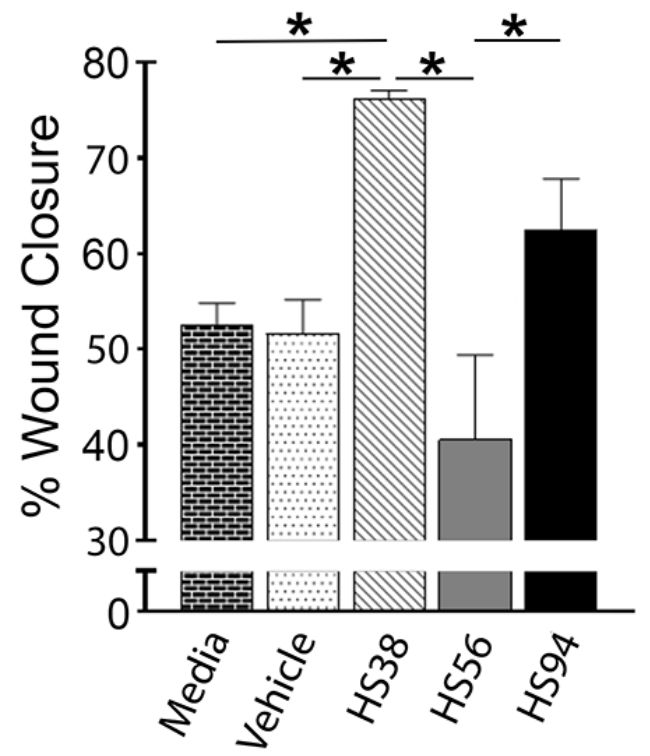

D

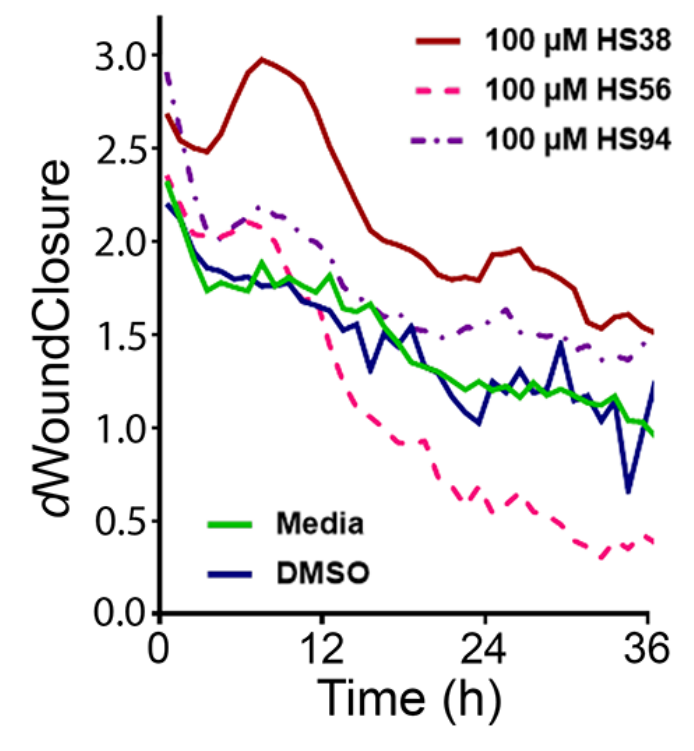


bioRxiv preprint doi: https://doi.org/10.1101/2021.12.03.471118; this version posted December 3, 2021. The copyright holder for this preprint (which was not certified by peer review) is the author/funder, who has granted bioRxiv a license to display the preprint in perpetuity. It is made available under aCC-BY-NC-ND 4.0 International license.

\section{FIGURE 3}

A
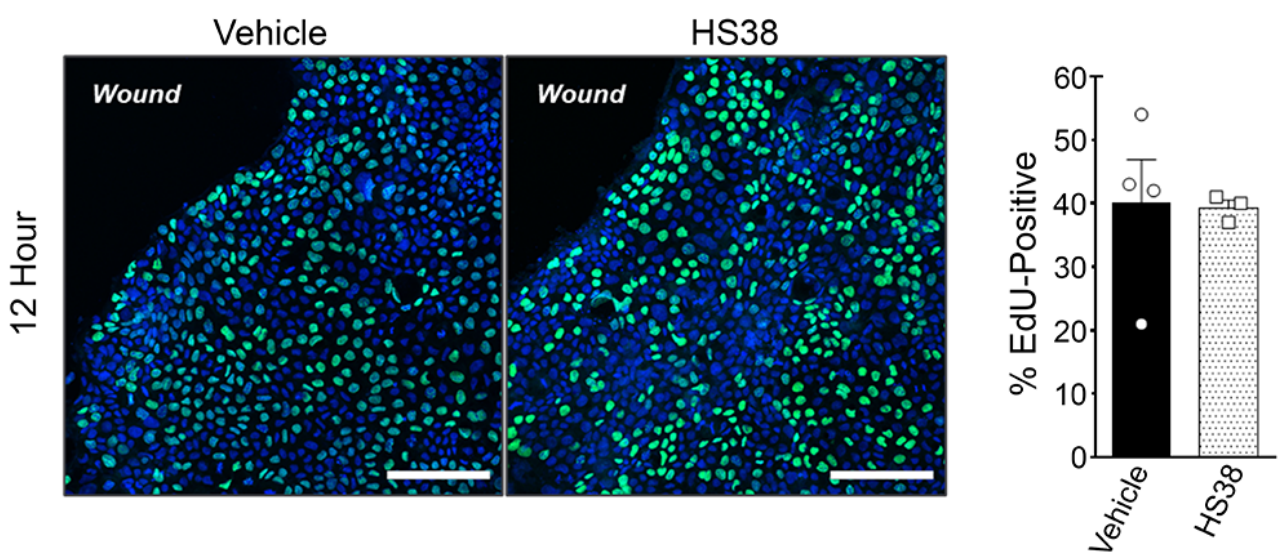

B
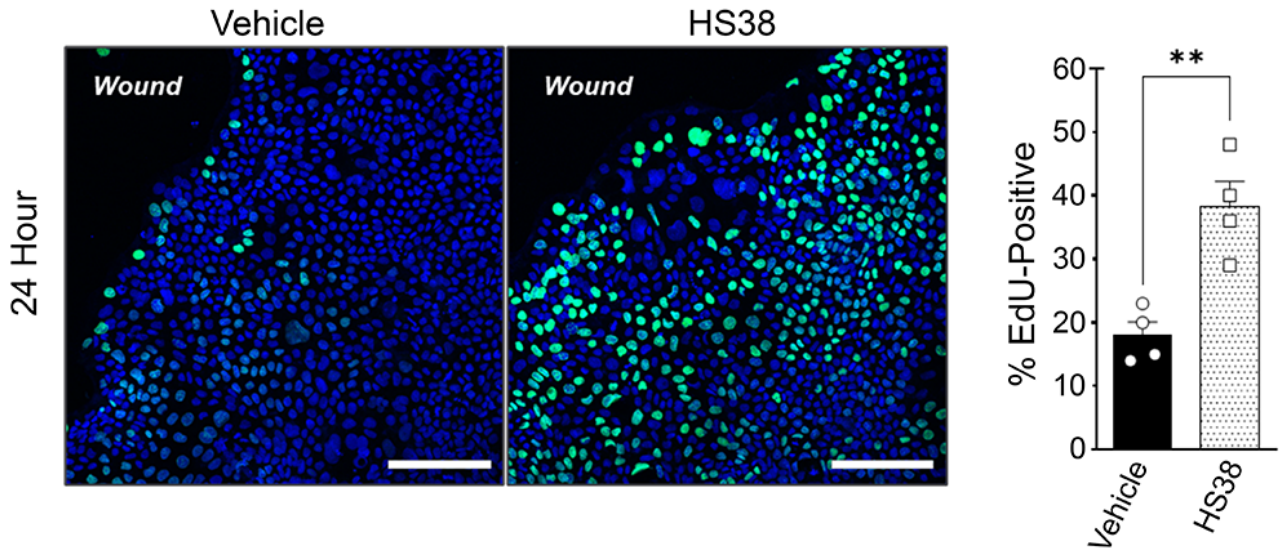

C
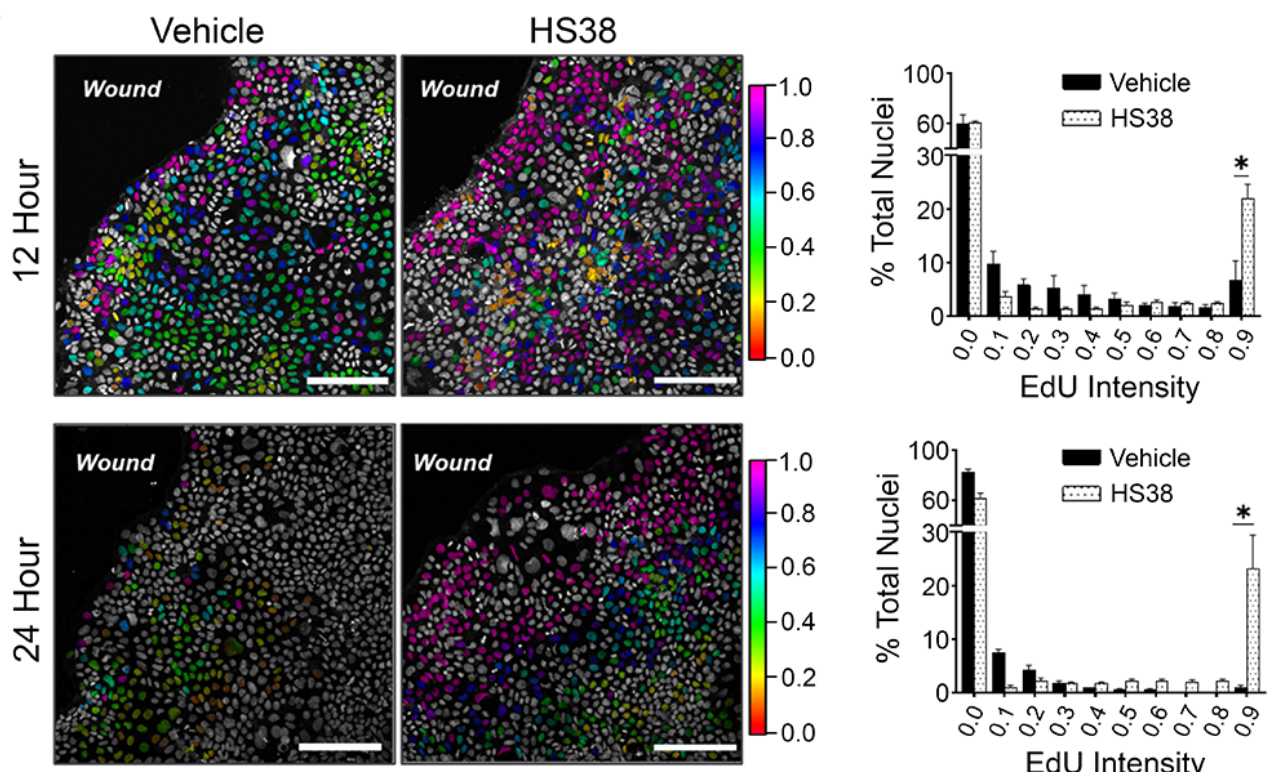

EdU Intensity 
bioRxiv preprint doi: https://doi.org/10.1101/2021.12.03.471118; this version posted December 3, 2021. The copyright holder for this preprint (which was not certified by peer review) is the author/funder, who has granted bioRxiv a license to display the preprint in perpetuity. It is made available under aCC-BY-NC-ND 4.0 International license.

FIGURE 4

A
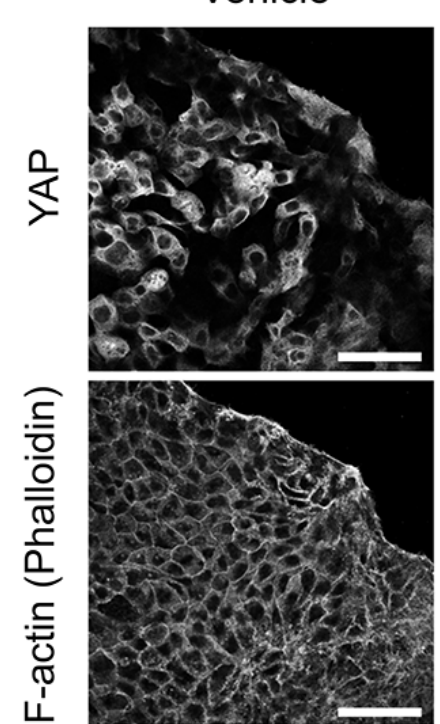

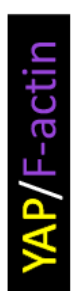
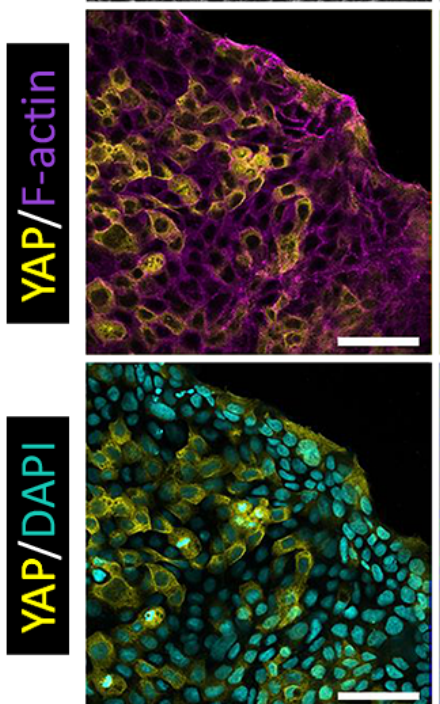

HS38
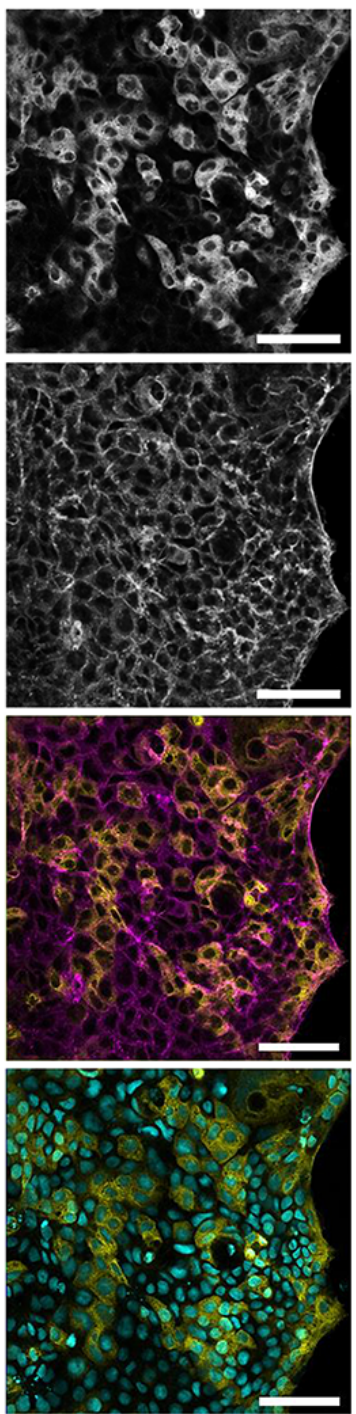

B
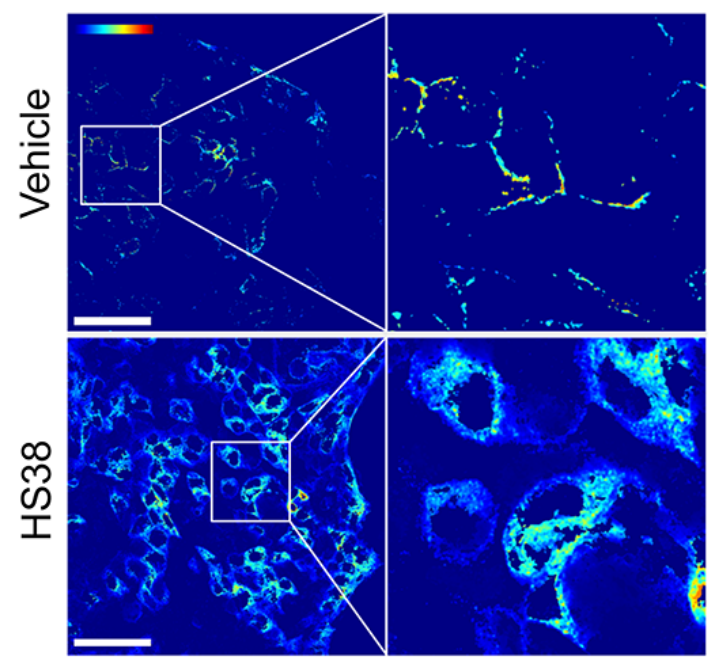

C

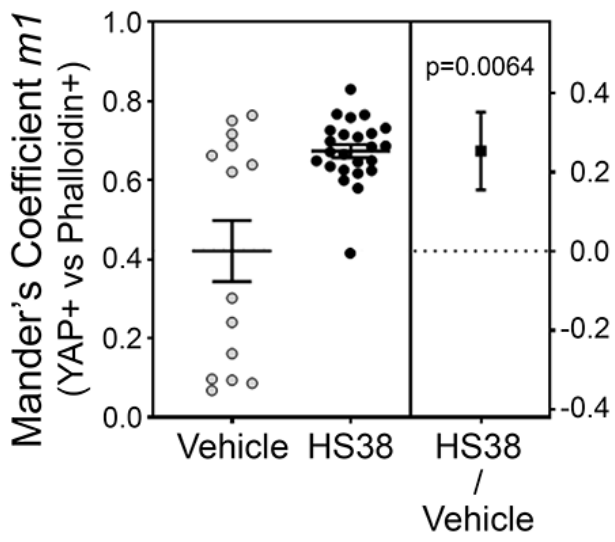


bioRxiv preprint doi: https://doi.org/10.1101/2021.12.03.471118; this version posted December 3, 2021. The copyright holder for this preprint (which was not certified by peer review) is the author/funder, who has granted bioRxiv a license to display the preprint in perpetuity. It is made available under aCC-BY-NC-ND 4.0 International license.

FIGURE 5

A

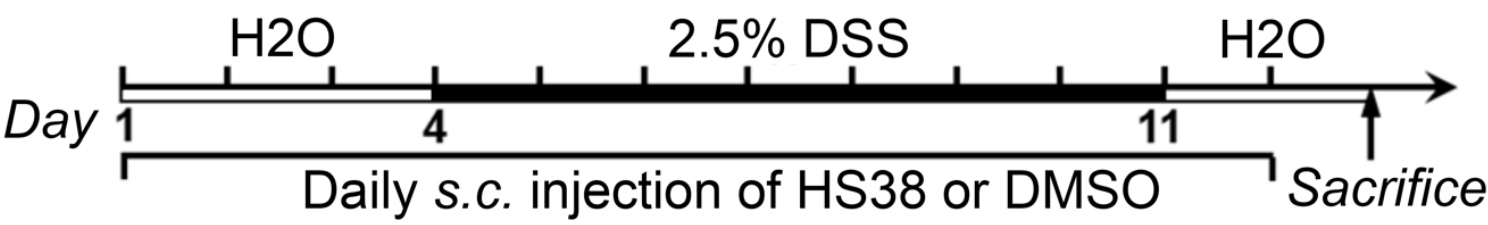

B

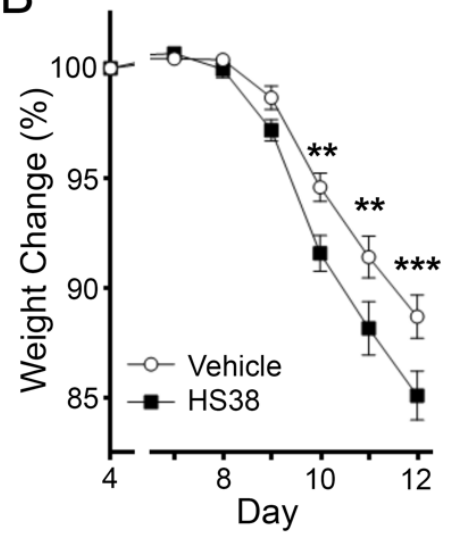

C

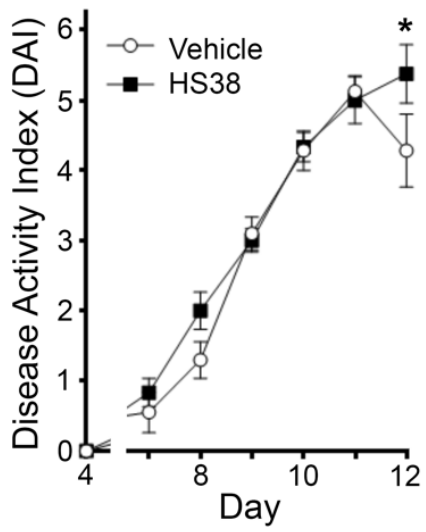

D

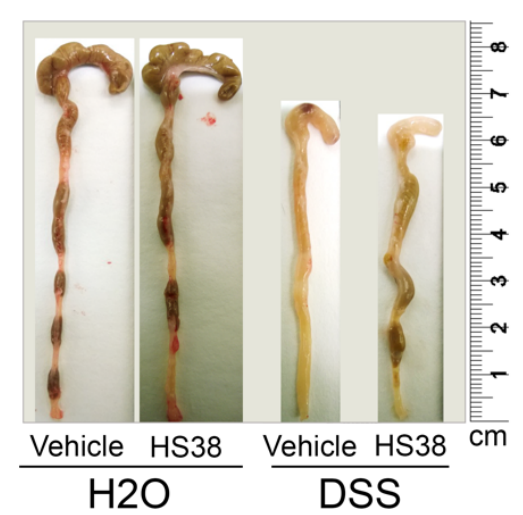

$E$

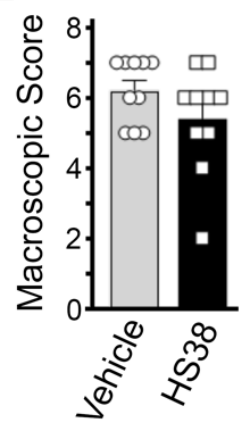

$\mathrm{F}$

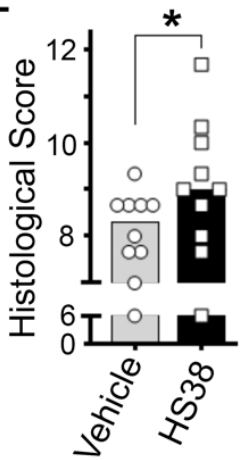

G
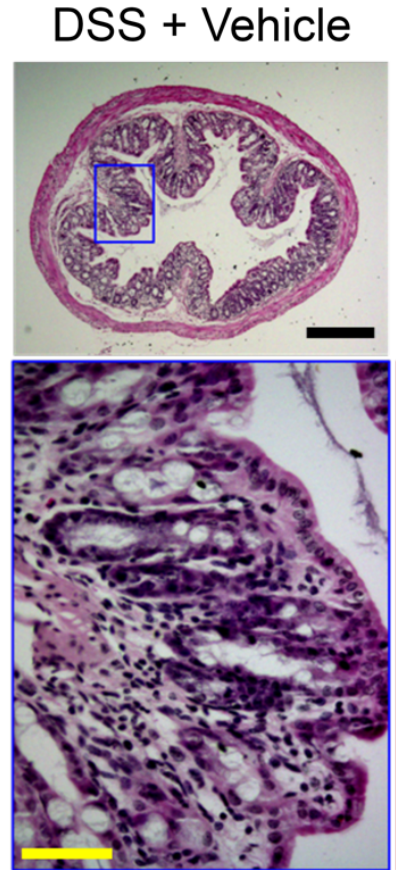

DSS + HS38

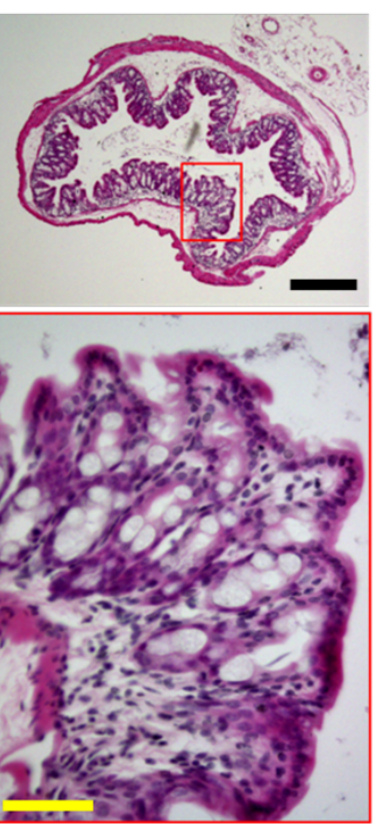

$\mathrm{H}$
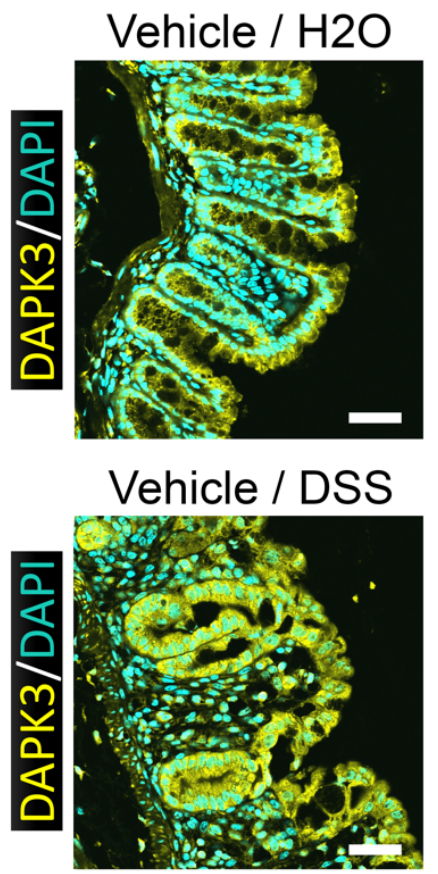
FIGURE 6

A

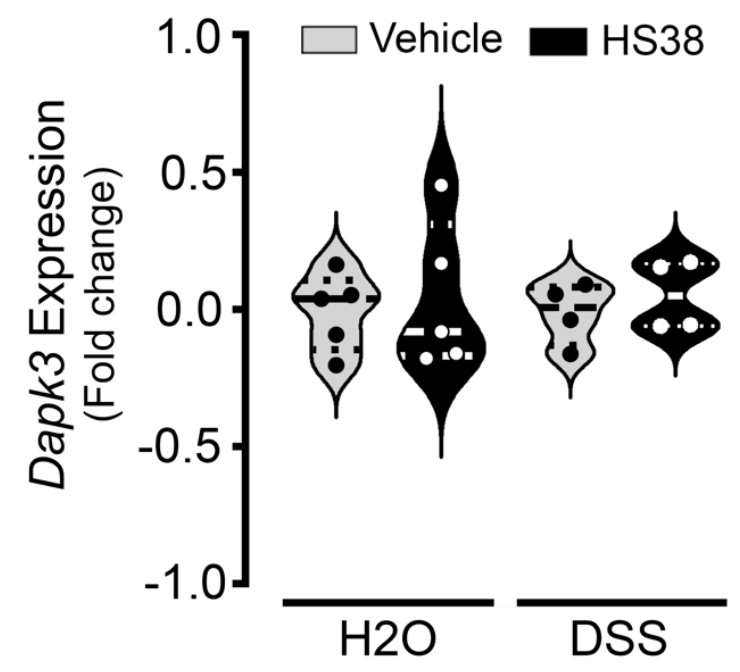

C

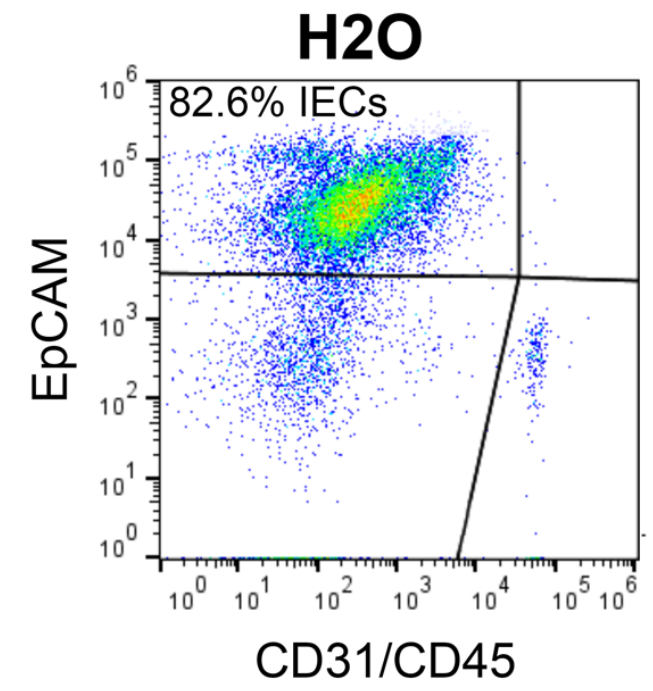

B
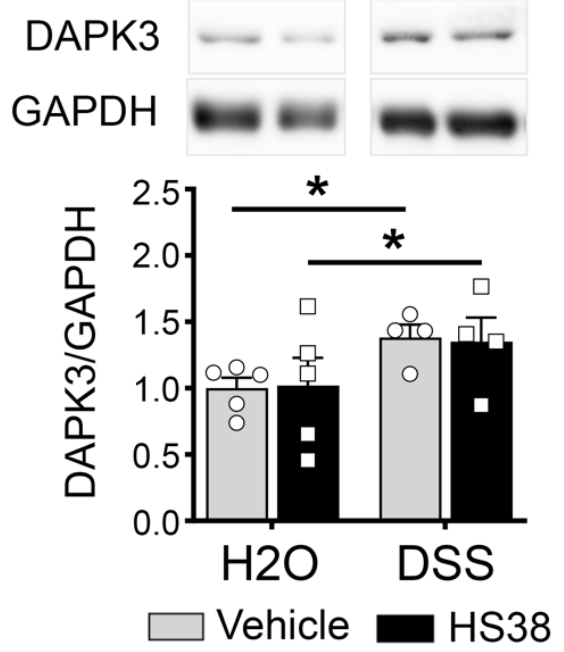

DSS

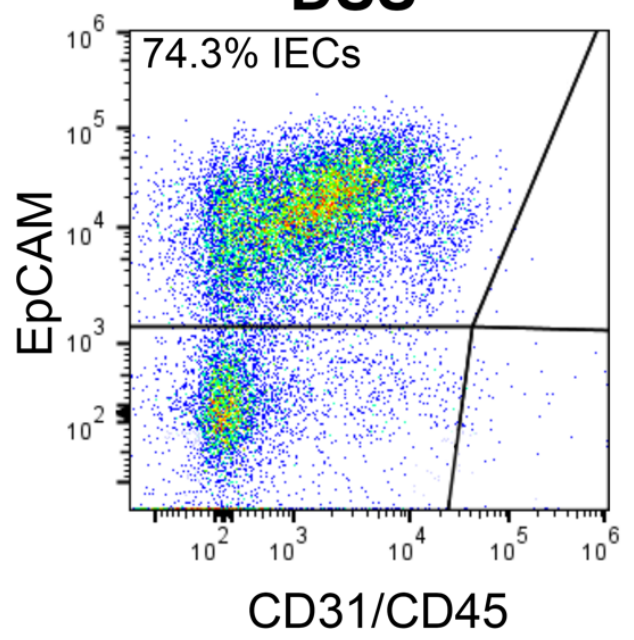




\section{FIGURE 7}

A
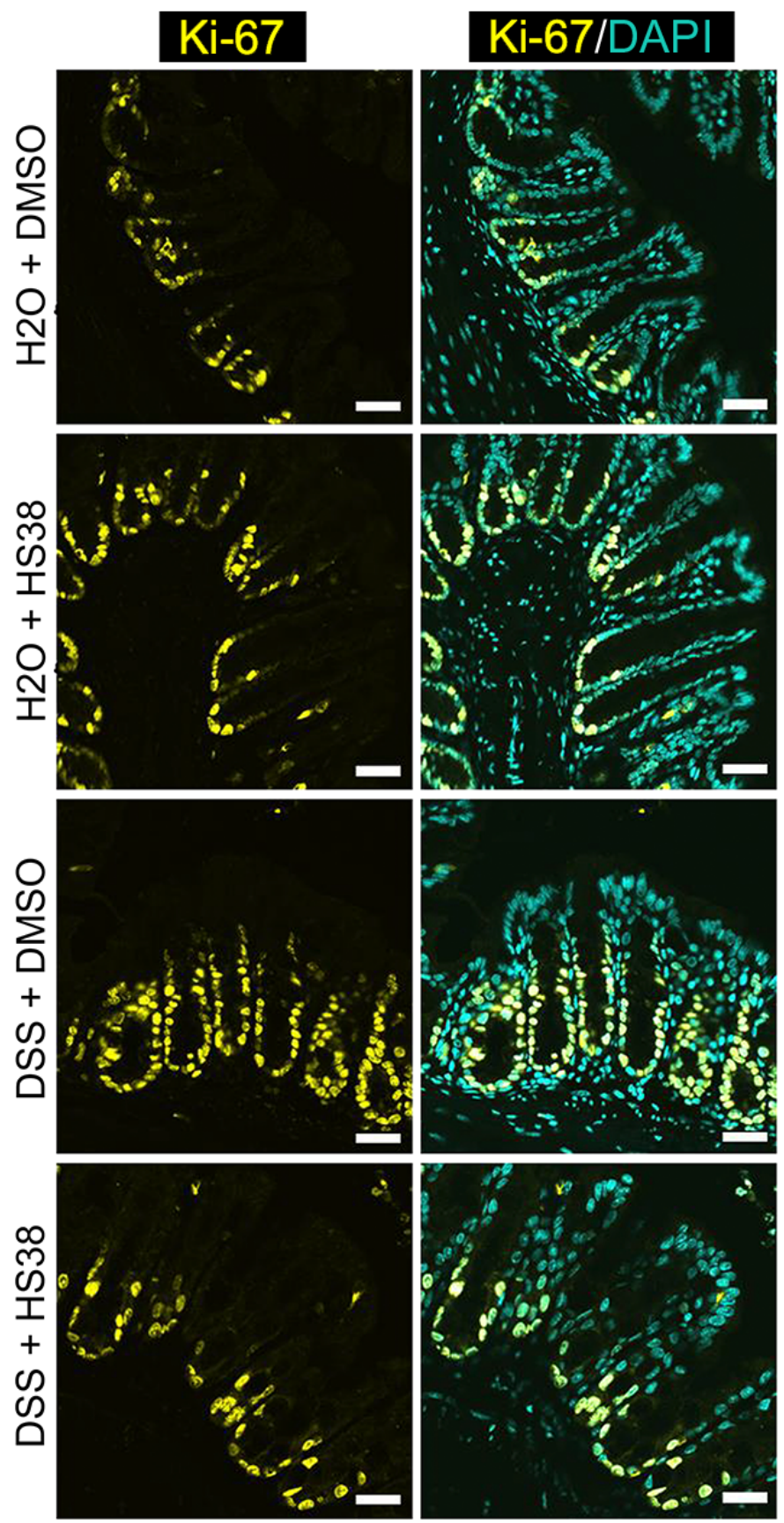

B

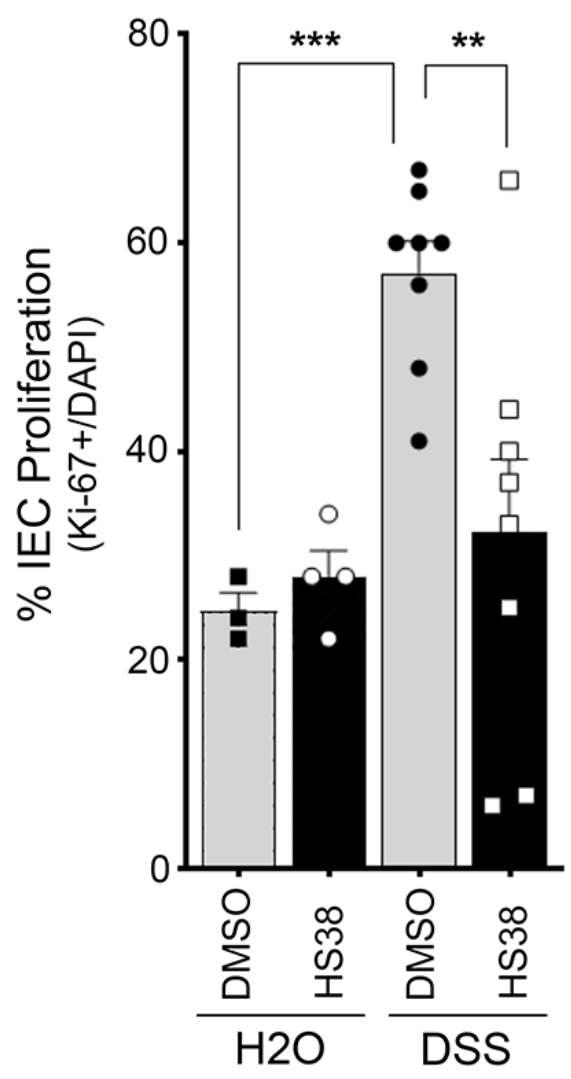




\section{FIGURE 8}
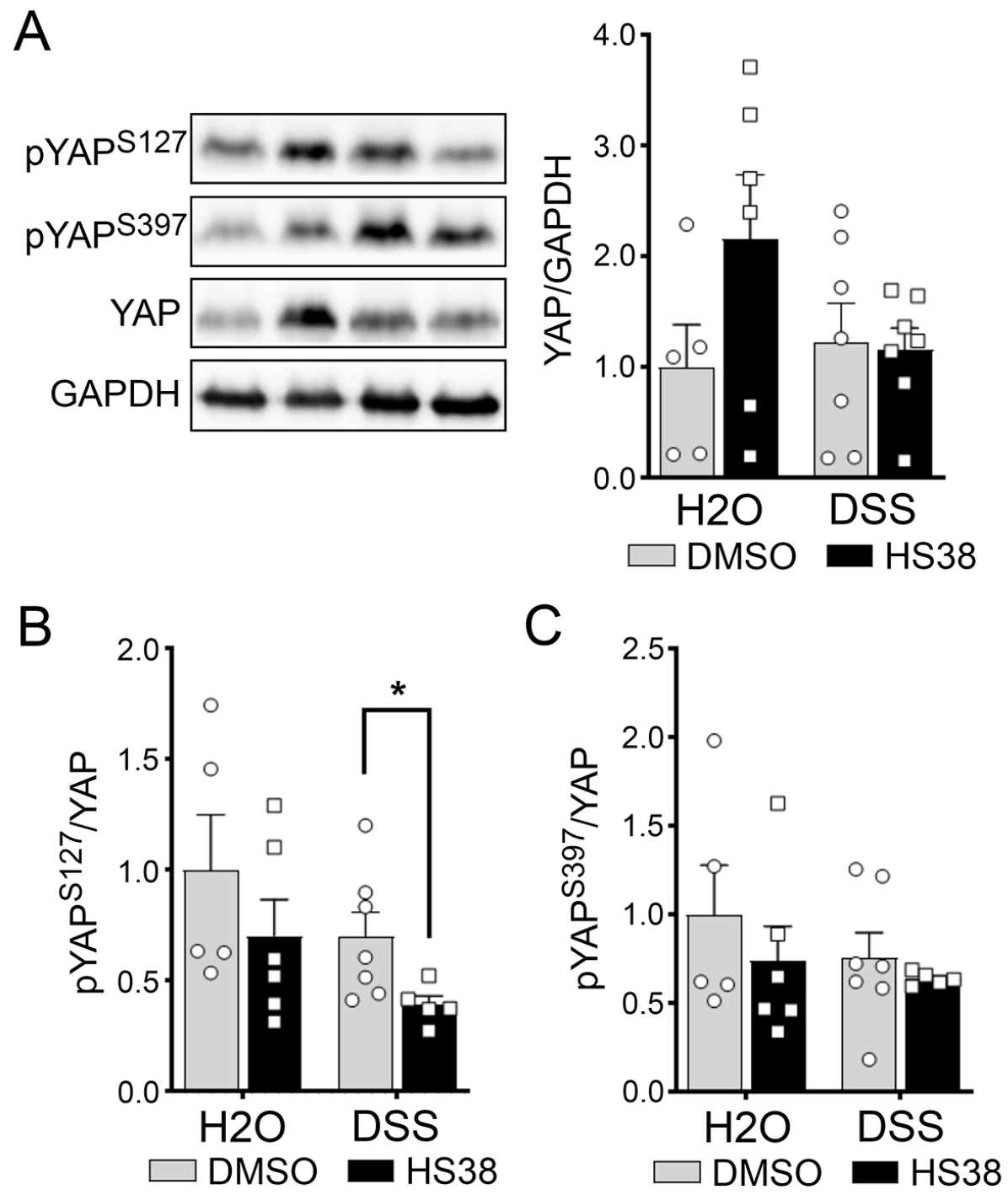
FIGURE 9

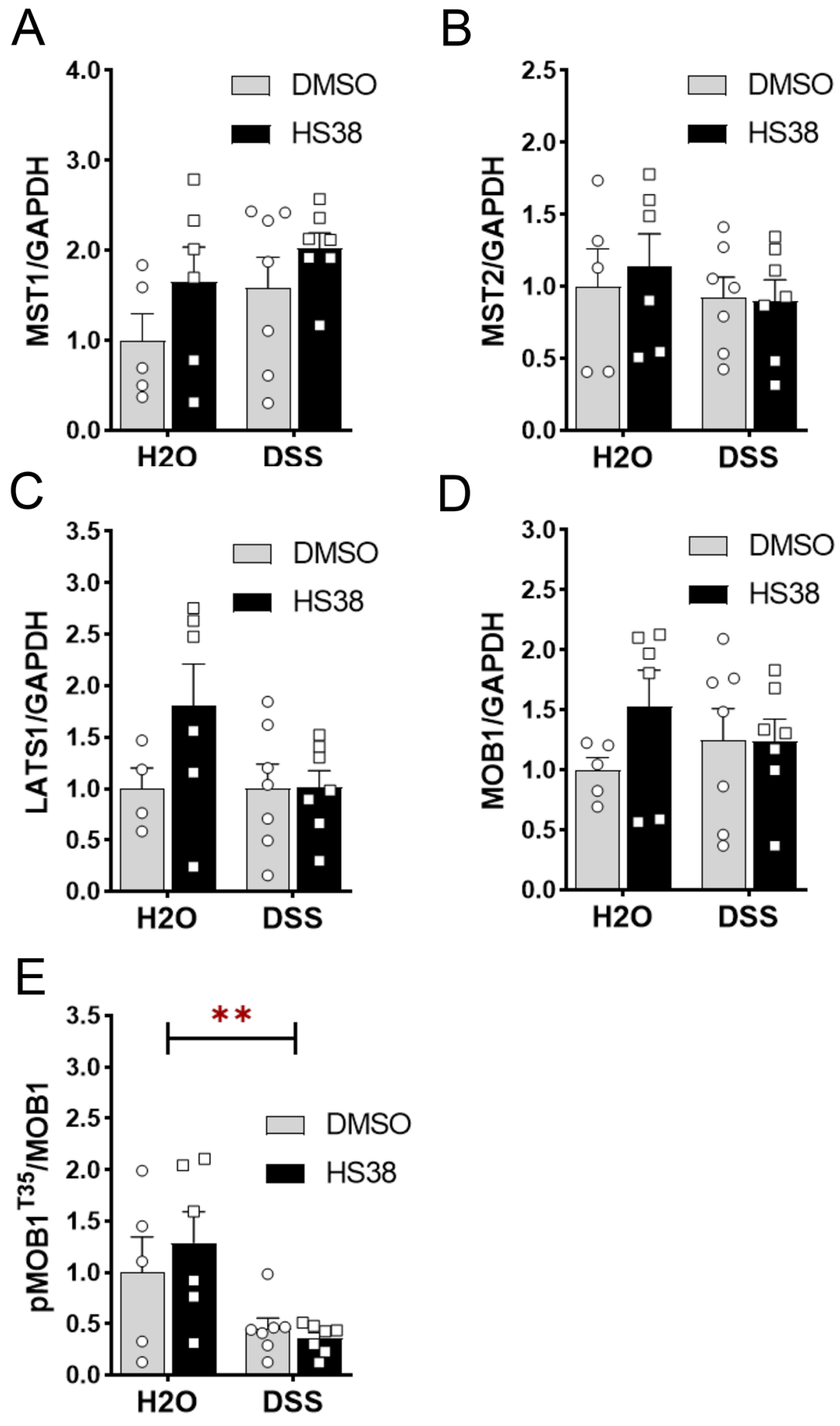


bioRxiv preprint doi: https://doi.org/10.1101/2021.12 03.471118; this version posted December 3, 2021. The copyright holder for this preprint (which was not certified by peer review) is the author/funder, who has granted bioRxiv a license to display the preprint in perpetuity. It is made available under aCC-BY-NC-ND 4.0 International license.

FIGURE 10

A

DSS + Vehicle

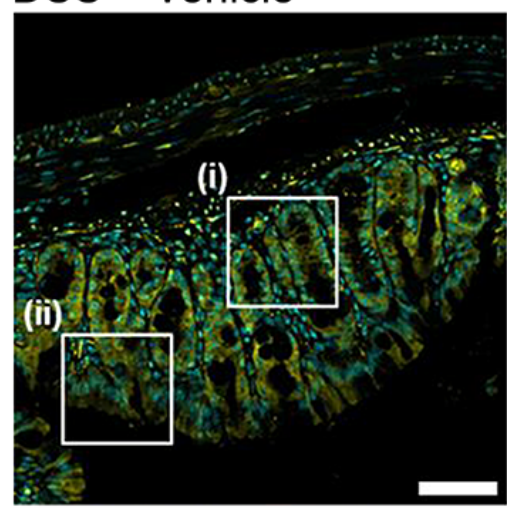

B

\section{DSS + HS38}

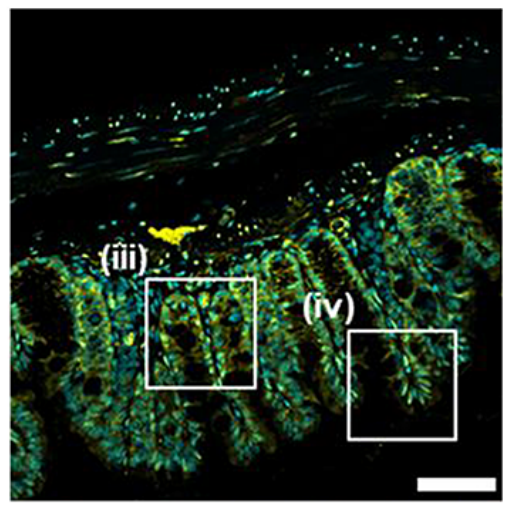

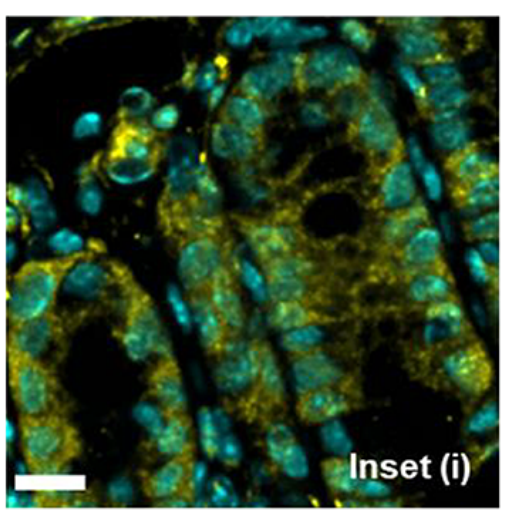
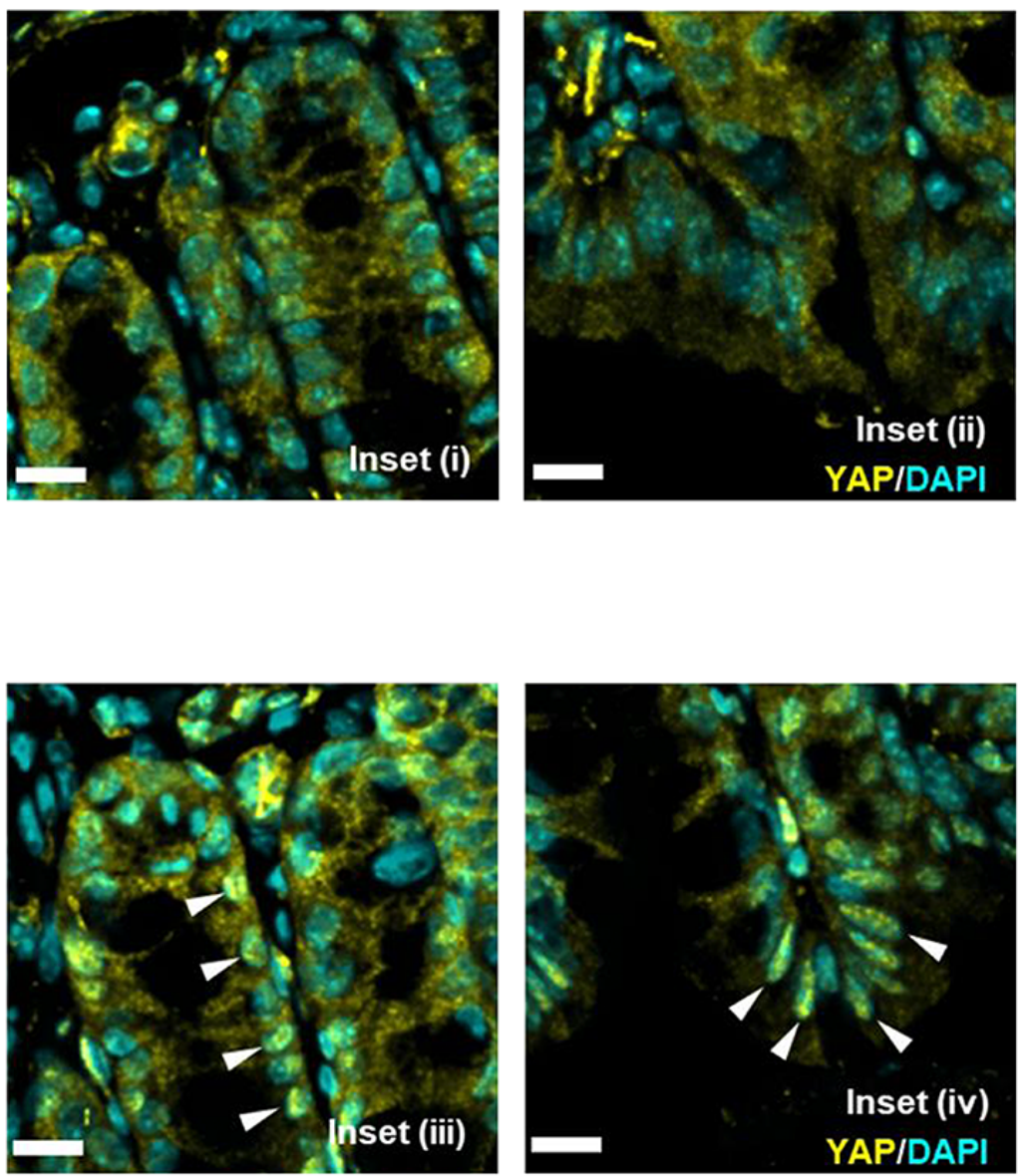